University of Michigan Law School

University of Michigan Law School Scholarship Repository

Law \& Economics Working Papers

6-1-2014

\title{
Carrot or Stick? The Shift from Voluntary to Mandatory Disclosure of Risk Factors
}

Karen K. Nelson

k.nelson@tcu.edu

Adam C. Pritchard

University of Michigan Law School, acplaw@umich.edu

Follow this and additional works at: https://repository.law.umich.edu/law_econ_current

Part of the Securities Law Commons

\section{Working Paper Citation}

Nelson, Karen K. and Pritchard, Adam C., "Carrot or Stick? The Shift from Voluntary to Mandatory Disclosure of Risk Factors" (2014). Law \& Economics Working Papers. 104.

https://repository.law.umich.edu/law_econ_current/104

This Article is brought to you for free and open access by University of Michigan Law School Scholarship Repository. It has been accepted for inclusion in Law \& Economics Working Papers by an authorized administrator of University of Michigan Law School Scholarship Repository. For more information, please contact mlaw.repository@umich.edu. 


\title{
Carrot or Stick? The Shift from Voluntary to Mandatory Disclosure of Risk Factors
}

\author{
Karen K. Nelson \\ Rice University \\ Jones Graduate School of Business \\ Houston, TX 77005 \\ (713) 348-5388 \\ nelsonk@rice.edu \\ A. C. Pritchard \\ University of Michigan Law School \\ Ann Arbor, MI 48109 \\ (734) 647-4048 \\ acplaw@umich.edu
}

June 2014

\begin{abstract}
This study investigates risk factor disclosures under the voluntary, incentive-based disclosure regime provided by the safe harbor provision of the Private Securities Litigation Reform Act and the SEC's subsequent disclosure mandate. Firms subject to greater litigation risk disclose more risk factors, update the language more from year-to-year, and use more readable language than firms with lower litigation risk. These differences in the quality of disclosure are pronounced in the voluntary disclosure regime, but converge following the SEC mandate. Consistent with these findings, the risk factor disclosures of high litigation risk firms are significantly more informative about systematic and idiosyncratic firm risk when disclosure is voluntary but not when disclosure is mandated. Overall, the results suggest that for some firms voluntary disclosure of risk factors is not a substitute for a regulatory mandate.
\end{abstract}

Keywords: risk factors; disclosure regulation; litigation risk; information content.

Data Availability: All data are available from public sources.

We appreciate helpful comments and suggestions from Rob Bloomfield, Steve Crawford, Steve Huddart, Wayne Landsman, Ray Pfeiffer, Sue Porter, Richard Price, Kevin Rich, Brian Rountree, Mary Stanford, Teri Yohn, and workshop participants at George Washington University, University of Massachusetts, University of Michigan, University of Minnesota, Penn State University, Rice University, Vanderbilt University, the 2007 Lone Star Accounting Conference, the 2007 Annual Meeting of the American Association of Law Schools, the 2007 Murphy Conference at the Fordham University School of Law, the 2007 Conference on Empirical Legal Studies, and the 2008 American Accounting Association Annual Meeting. A previous version of this paper was circulated under the title "Litigation Risk and Voluntary Disclosure: The Use of Meaningful Cautionary Language." Scott Baggett, Mac Gaulin, and Claire Harvey provided valuable research assistance. 


\section{Introduction}

Theories of voluntary disclosure emphasize that managers generally are eager to share their firms' positive outlook, but they may be less forthcoming with bad news. Empirical evidence supports this proposition; for example, Kothari et al. (2009) finds that managers delay the release of bad news to investors. What about the potential for bad news? Investors assessing the value of a firm's securities are interested in the likelihood of both good and bad outcomes in forecasting the firm's future cash flows. In the extreme, positive projections could be rendered misleading by the omission of potential risks that might thwart the firm's plans and aspirations.

This paper examines public companies' disclosure of risk factors that are meant to inform investors about risks and uncertainties. In 1995, Congress created a legal incentive to disclose risk factors as part of the Private Securities Litigation Reform Act (PSLRA). The PSLRA's safe harbor provision shields firms from liability for forward-looking statements provided they are accompanied by "meaningful cautionary statements identifying important factors that could cause actual results to differ materially from those in the forward looking statement." The voluntary disclosure of risk factors provides a direct means for firms to reduce the often substantial expected costs of securities fraud class actions. Thus, the safe harbor provides an important incentive for public companies to disclose risk factors, but that incentive is likely to vary with firms' perception of their potential vulnerability to securities class actions.

Risk factor disclosure shifted from a voluntary, incentive-based regime to a mandatory one in 2005 when the SEC added Item 1A to Form 10-K, requiring most public companies to disclose risk factors annually and update them quarterly as necessary in Form 10-Q. In adopting the new rule, the SEC acknowledged that some issuers had already been disclosing risk factors to take advantage of the PSLRA's safe harbor. 
We study how these two changes in the law affect the disclosure of risk factors. We conjecture that litigation risk plays an important role in firms' disclosure practices, particularly during the voluntary disclosure period from 1996 to 2005 . Further, we expect that the SEC's 2005 disclosure mandate will narrow, but not necessarily close, the gap between firms with a litigation-related incentive to provide risk factor disclosure and those compelled to disclose because of the mandate. Finally, we expect that differences in the quality of the disclosure are likely to affect its usefulness to investors in assessing firm risk.

To conduct our analyses, we construct a sample of firms with high ex-ante risk of being sued in a securities fraud class action and a sample with low ex-ante risk of being sued. We examine risk factors disclosed by these firms in annual reports filed with the SEC from 19962010 using three metrics designed to capture characteristics of "meaningful" disclosure suggested by the PSLRA's legislative history, subsequent court decisions, and the SEC: (i) the amount of risk factor disclosure, measured with the number of words; (ii) the extent to which the risk factors are updated year-to-year, measured with the Resemblance score of text similarity; and (iii) the readability of the risk factors, measured using the Fog index of text complexity. All else equal, risk factor disclosure is more "meaningful" if it is comprehensive, if it is not a boilerplate copy from the prior year, and if it can be understood by the average investor.

We use these disclosure metrics to investigate whether firms at greater risk of securities fraud lawsuits provide more "meaningful" risk factor disclosure, and how the SEC's 2005 mandate affects this disclosure. Controlling for other factors that could affect the disclosure decision, we find that, on average, firms with greater litigation risk provide more risk factor disclosure, revise their disclosure more from year-to-year, and use more readable language than firms with low litigation risk. When we allow these effects to vary with the disclosure regime, 
we find significant differences in disclosure between high and low risk firms in the voluntary regime. After the SEC mandate in 2005, however, firms with low litigation risk increase the amount of risk factor disclosure, revise it more extensively each year, and use more readable language, thus leading to more similar disclosure across the two groups of firms.

Our conclusion is that the SEC's mandate had a material effect on the disclosure decisions of companies that had relatively little incentive to provide meaningful disclosure under the PSLRA's safe harbor provision alone. This is not to say, however, that litigation-related disclosure incentives have no role to play in the mandatory disclosure regime. We find that firms with high litigation risk continue to provide a significantly greater amount of risk factor disclosure in the mandatory regime. Moreover, in both disclosure regimes, high risk firms disclose significantly more risk factor information as litigation risk increases.

We also find evidence that risk factor disclosures provide information useful to investors in assessing future firm risk, although here again the findings vary predictably with firms' disclosure incentives and the disclosure regime. For firms with high litigation risk and hence greater incentive to provide meaningful disclosure, one-year-ahead beta and stock return volatility are increasing in the unexpected portion of risk factor disclosure. Moreover, in the voluntary disclosure regime, firms with high litigation risk provide risk factor disclosures that are significantly more informative about systematic and idiosyncratic risk than firms with low litigation risk. Subsequent to the SEC mandate, however, there is no statistical difference, consistent with a convergence in the meaningfulness of risk factor disclosures.

Overall, our findings are consistent with managers responding to high ex ante litigation risk with risk factor disclosures designed to reduce the expected costs of litigation. In contrast, low risk firms perceiving little net benefit to disclosure did not provide meaningful risk factor 
disclosure until compelled to do so by the SEC. Understanding risk factor disclosures is important to managers and legal counsel responsible for formulating a disclosure strategy, to regulators and courts charged with evaluating the quality of these disclosures, and to investors interested in assessing the risks posed by firms.

We proceed as follows. Section 2 provides institutional background on the evolution of risk factor disclosures in regulatory filings. Section 3 surveys related research. Section 4 develops our hypotheses. Section 5 describes our research design, and Section 6 presents the results of our empirical tests. Section 7 concludes.

\section{Evolution of Risk Factor Disclosures}

For many years, risk factors were disclosed primarily by domestic companies registering public offerings on Form S-1 and foreign private issuers on Form 20-F annual reports. Over the past two decades, two regulatory changes progressively broadened the set of firms disclosing risk factors. The first, the enactment of the PSLRA in December 1995, provided an incentive to voluntarily disclose risk factors for firms wishing to avail themselves of its statutory safe harbor for forward-looking statements. ${ }^{1}$ Ten years later in December 2005, the SEC approved a rule mandating disclosure of risk factors in periodic filings. This section discusses the regulatory background and requirements of these two rule changes affecting risk factor disclosures.

\subsection{PSLRA Safe Harbor and the Voluntary Disclosure of Risk Factors}

In enacting the PSLRA, Congress expressed concern that securities class actions were discouraging managers from providing forward-looking information to investors. The PSLRA addresses that issue by creating a statutory safe harbor protecting written or oral statements that are identified as forward-looking and "accompanied by meaningful cautionary statements

\footnotetext{
${ }^{1}$ Although the SEC adopted a limited safe harbor for forward-looking disclosures in 1979, its reach is narrow, providing very limited protection against liability.
} 
identifying important factors that could cause actual results to differ materially from those in the forward looking statement." courts, allowing firms to invoke the safe harbor by including language regarding risk factors in their periodic filings with the SEC and incorporating that disclosure by reference in subsequent communications containing forward-looking statements. ${ }^{3}$

The statute does not explicitly define, however, what constitutes a "meaningful" cautionary statement, although legislative history and court decisions provide some insights. In particular, the Conference Report (1995) states that "cautionary statements must convey substantive information about factors that realistically could cause results to differ materially from those projected in the forward-looking statements." Thus, courts have concluded that a "cursory" discussion of risk factors will not invoke the protections of the safe harbor. ${ }^{4}$

The Conference Report (1995) also states that "boilerplate warnings will not suffice." For the discussion of risk factors to be meaningful, it must change as the firm's circumstances change. Accordingly, courts have ruled that when a firm's "cautionary language remained fixed even as the risks changed," it was insufficient to warrant the protection of the safe harbor. ${ }^{5}$

Finally, courts have ruled that cautionary risk factor statements will not satisfy the safe harbor's requirements if they are "too cryptic to be meaningful to the average investor." the prescriptions found in the PSLRA's legislative history and court decisions suggest that cautionary statements regarding risk factors should be thorough, should not cut and paste

\footnotetext{
${ }^{2}$ See Johnson et al. $(2000 ; 2001)$ for additional discussion of the PSLRA's legislative history and the safe harbor.

${ }^{3}$ For example, firms will often reference the risk factors discussed in their securities filings in their corporate press releases or investor conference calls.

${ }^{4}$ See, for example, Helwig v. Vencor, Inc., 251 F.3d 540, 559 (6 ${ }^{\text {th }}$ Cir. 2001) and Yanek v. Staar Surgical Co., 388 F.Supp.2d 1110, 1123 (C.D. Cal. 2005). The statute does not, however, require a firm to disclose all risk factors that could cause future results to differ from those projected, or the particular risk factor that ultimately causes the forward-looking statement to be in error. See Conference Report (1995) and Harris v. IVAX, Corp., 182 F.3d 799, 807 (11 $1^{\text {th }}$ Cir. 1999).

${ }_{6}^{5}$ Asher v. Baxter International, Inc. 377 F.3d 727 ( $7^{\text {th }}$ Cir. 2004).

${ }^{6}$ In re Nike, Inc. Sec. Litig., 181 F.Supp.2d 1160, 1172 (D. Or.2002).
} 
boilerplate language from the preceding year, and should be written in language easily

understood by the average investor.

\subsection{SEC Risk Factor Disclosure Mandate}

In 2005, the SEC streamlined considerably the public offering process under the Securities Act of 1933 (SEC 2005). In addition to these changes, the SEC also imposed several new disclosure requirements on public companies pursuant to the Exchange Act. Notable for our purposes is a new requirement that most public companies disclose the most significant factors that may adversely affect the issuer's business, operations, industry, financial position, or its future financial performance. The risk factors are required to be presented in Item 1A of Form $10-\mathrm{K}$ and must be updated quarterly in the $10-\mathrm{Q}$ to reflect material changes from previously disclosed risks. ${ }^{7}$

The SEC rule does not require particular risk factors be disclosed. Instead, it notes that disclosures should be clearly written in everyday language investors can read and understand, in accordance with the SEC's plain English standards, and should avoid "boilerplate" discussion of risks that could affect any issuer. Consistent with these prescriptions, the SEC has called on companies to provide more information on the risks they face and to avoid "copying and pasting" from earlier filings (Johnson 2010). Thus, as under the PSLRA, risk factor disclosures should be thorough, updated year-to-year, and readable. In our research design discussed below, we develop measures to capture these three facets of risk factor disclosures.

\footnotetext{
${ }^{7}$ Smaller reporting companies and asset-backed issuers are excluded from the disclosure requirement are. At the time the SEC implemented securities offering reform, small public companies were allowed to follow the reduced disclosure requirements of Regulation S-B. The Smaller Reporting Company rule, adopted by the SEC effective February 4, 2008, consolidated Regulation S-B into Regulation S-K and effectively expanded the number of smaller companies eligible to follow the reduced disclosure requirements. Firms identifying themselves as "smaller reporting companies" may adopt reduced disclosure requirements on an item-by-item basis, including the option to forego Item $1 \mathrm{~A}$ risk factor disclosures.
} 


\section{Related Research}

This paper contributes to our understanding of how law and regulation shape managers' response to disclosure incentives and mandates. In particular, we contribute to three inter-related streams of literature regarding: (1) voluntary versus mandatory disclosure; (2) risk disclosures; and (3) the link between disclosure and litigation risk.

\subsection{Voluntary versus Mandatory Disclosure}

The earliest work on disclosure regulation examines the market reaction to the passage of the Securities Act of 1933, which allows the SEC to mandate disclosure in public offerings. Stigler (1964) and Jarrell (1981) find no evidence that securities offered after the Securities Act provide investors with greater returns, although they do find that post-legislation offerings demonstrate less variance. Less variance may be evidence that investors are better able to assess risk with mandatory disclosure, or it may simply reflect riskier offerings moving to private placements (Benston, 1969; Jarrell, 1981; Simon, 1989).

Other work examines the extension of mandatory disclosure requirements to new segments of the capital markets. Ferrell (2003) investigates the effect of the 1964 extension of periodic disclosures required under the Exchange Act to the over-the-counter market. He finds that the changes are associated with a significant reduction in volatility for the affected securities. Greenstone et al. (2006) shows positive abnormal stock returns and an increase in operating performance for firms brought in to the disclosure regime by the 1964 amendments. Related to this work, Bushee and Leuz (2005) finds that the extension of the Exchange Act disclosure requirements to the OTC-Bulletin Board in 1999 results in positive abnormal returns for OTC-BB firms already subject to the disclosure requirements, suggesting externality effects from disclosure. However, they also find that the imposition of SEC disclosure requirements 
forced a large number of firms into the less regulated Pink Sheets. Moreover, the OTC firms that chose to comply with the new disclosure requirements to continue trading on the OTC-BB experienced, on average, negative abnormal returns.

Although most research examines the imposition of mandatory disclosure requirements, Cheng et al. (2013) examines the SEC's 2008 decision to exempt companies under \$75 million in market capitalization from certain disclosure requirements. They find that firms choosing to voluntarily continue such disclosures after the regulatory change nonetheless experience a drop in liquidity, although the decline is not as great as it is for firms that stop disclosing. They interpret their results as supporting the argument that mandatory disclosure serves as a credible commitment device that perhaps cannot be duplicated by voluntary disclosure.

\subsection{Risk Disclosures}

Early research in this area examines mandatory quantitative disclosures detailing firms' market risk exposures (e.g., Rajgopal, 1999; Linsmeier et al., 2002; Jorion, 2002). The findings show that these disclosures are correlated with market-based measures of risk and equity prices. More recent work uses textual analysis tools to analyze qualitative risk disclosures. For example, Li (2006) counts the frequency of the word stems "risk" and "uncertain" over a sample period that pre-dates the risk factor disclosure mandate, 1993 to 2004, and finds that an increase in the risk sentiment of annual reports is associated with lower future earnings and equity returns. Kravet and Muslu (2013) counts the number of sentences containing risk-related keywords in corporate annual reports over a sample period that spans both the PSLRA safe harbor and the risk factor disclosure mandate, 1994 to 2007, and finds that increases in this measure are associated with increased stock return volatility and trading volume around the $10-\mathrm{K}$ filing date, as well increased volatility of analyst forecast revisions. Campbell et al. (2014) examines the 
number of words and specific keywords in Item 1A over the post-mandate period, 2005-2008, and finds a positive association between the length of risk factor disclosures and post-disclosure market beta and stock return volatility.

\subsection{Litigation Risk and Disclosure}

The relation between litigation risk and disclosure is complex. On the one hand, high litigation risk can reduce managers' incentives to provide forecasts. For example, Rogers and Van Buskirk (2009) finds that firms reduce disclosure in the immediate aftermath of a lawsuit filing. Baginski et al. (2002) reports that firms in the U.S. issue fewer forecasts of both good and bad news than do firms in the less litigious Canadian environment. Moreover, U.S. firms were significantly less likely to provide forecasts before the PSLRA's safe harbor provision was enacted increasing protection for forward-looking disclosures (Johnson et al. 2001).

On the other hand, when faced with bad news, managers have an incentive to provide an early warning of the earnings shortfall to reduce the likelihood and expected costs of litigation (Skinner, 1994; Kasznik and Lev, 1995). Although timely disclosure of bad news does not always deter the filing of a lawsuit (Francis et al. 1994), it can deter certain types of lawsuits (Field et al. 2005) and reduce the expected costs of resolving litigation (Skinner 1997).

\subsection{Contribution}

We extend the literature summarized above in several important directions. We provide direct evidence on how a shift from a regime providing incentives for voluntary disclosure to one requiring disclosure affects the disclosed information and its usefulness to investors. Prior research on disclosure regulation generally infers the consequences of a disclosure mandate from its capital market effects without directly linking the market response to disclosure practices and attributes under the alternative regimes. Moreover, we also consider whether the requirement to 
disclose an item affects the quality of disclosures for the firms that already voluntarily provide the information, an important issue that has not been addressed in the literature.

With respect to our particular focus on risk factor disclosures, prior research does not consider the effects of changes in disclosure regime. Moreover, these studies generally focus on a single disclosure property, most often the amount of disclosure, whereas we develop and test predictions for three complementary measures that explain variation in risk factor disclosures in general and in relation to MD\&A. Finally, this work, and prior textual analysis research in general, gives little consideration to managers' disclosure incentives (Li, 2010). We examine the complementary role of legal incentives and regulatory mandates on risk factor disclosures. Moreover, the focus of litigation-related disclosure research has been on managements' voluntary earnings forecasts. In this paper, we turn our attention to incentives to disclose risk factors in corporate annual reports as a preemptive means of controlling firms' exposure to litigation.

\section{Hypothesis Development}

Based on the institutional background and prior research discussed above, we develop a series of hypotheses for our empirical tests. In particular, we examine the association between the risk of securities fraud litigation and risk factor disclosures, firms' response to the SEC's 2005 disclosure mandate, and the relevance of risk factor disclosures to investors.

\subsection{Litigation Risk and Risk Factors}

All else equal, the greater the probability of litigation, the greater the expected benefits from disclosing risk factors under the PSLRA. Prior research presents empirical evidence consistent with the PSLRA's safe harbor reducing expected legal costs. For example, the likelihood an earnings warning will result in a lawsuit filing or an allegation of false or 
misleading projections is significantly lower after enactment of the PSLRA (Johnson et al. 2007), suggesting the safe harbor dissuades potential plaintiffs from pursuing disclosure-related complaints. Moreover, lawsuits containing allegations of fraud in forward-looking statements are more likely to be dismissed in the post-PSLRA period (Pritchard and Sale 2005), which also reduces defendants' legal costs from securities fraud class actions.

For some firms, however, the expected legal benefits of risk factor disclosure are likely minimal. Firms that are unlikely to be sued have little incentive to craft a meaningful risk factor discussion, especially when weighed against the potential business and personal costs of disclosure. Although the marginal administrative costs of formulating the disclosure are likely slight relative to the overall costs of preparing the $10-\mathrm{K}$, managers face a range of incentives to withhold unfavorable information (Kothari et al. 2009). Risk factors by their very nature convey information about a firm's vulnerabilities and potential adverse outcomes which could be exploited by competitors and investors, leading to negative career consequences for managers. Trading off these costs against the legal benefits of disclosure, firms are likely to minimize risk factors unless there is a nontrivial probability of being sued. ${ }^{8}$

To trigger safe harbor protection, risk factors must be "meaningful." We posit that firms at greater risk of litigation will provide more "meaningful" risk factor disclosure. As discussed above, the Conference Report (1995) states that risk factors must convey "substantive information." Given this prescription, and the courts' interpretation that risk factors are not meaningful if they are "cursory," we expect firms with higher litigation risk to provide more risk factor disclosure:

H1a: Firms at greater risk of litigation provide more risk factor disclosure.

\footnotetext{
${ }^{8} \mathrm{We}$ are not aware of any a priori reason to expect that the costs of disclosure, whether administrative, proprietary, or personal, are related to the ex-ante probability of being sued.
} 
The Conference Report (1995) also states that "boilerplate warnings" repeated from year to year are inadequate. Courts assessing the adequacy of firms' risk factors examine whether firms update their disclosed risks to reflect the current operating environment. The ordinary practice of managers and lawyers preparing SEC filings is to cut and paste from the previous filing, and then revise to reflect any developments in the business. If the risk factors are not adequately updated, they are less likely to provide protection against suit. Accordingly, we test the following hypothesis:

H1b: Firms at greater risk of litigation revise their risk factor disclosure more.

Courts have also held that risk factors must be comprehensible to provide a meaningful warning. As a result, they are likely to view risk factors that use excessive legalese or contain highly technical business terms as inadequate to secure safe harbor protection. Thus, we posit a positive association between litigation risk and the readability of risk factor disclosure:

H1c: Firms at greater risk of litigation provide more readable risk factor disclosure. The risk of securities litigation is not static; firms may vary in their exposure as their business environment changes. If firms with higher litigation risk have incentives to provide more meaningful risk factor disclosure, we expect an increase in litigation risk to trigger the disclosure of more risk factor information that is less boilerplate and more readable. Moreover, we expect the sensitivity of risk factor disclosure to increases in litigation risk to be especially acute for firms already at a high risk of being sued, as marginal changes in litigation exposure for low risk firms are unlikely to subject them to a substantial risk of a lawsuit. This line of reasoning leads to our second hypothesis:

H2: In response to an increase in litigation risk, firms at greater risk of litigation will provide more risk factor disclosure that is less boilerplate and more readable. 
We do not expect firms to respond to a decrease in litigation risk with a corresponding decrease in risk factor disclosure. Once a firm has identified and described a risk factor, the marginal cost of including it in subsequent filings is likely to be small. Even if a risk factor no longer provides substantial benefit in terms of reducing litigation exposure, there is likely to be a presumption favoring its continuance unless the factor becomes obviously irrelevant, such as "Year 2000" risk disclosures in 2001 and beyond.

\subsection{Disclosure Regulation and Risk Factors}

The SEC's 2005 risk factors disclosure requirement made mandatory a category of disclosure that was previously voluntary, albeit with a legal incentive to disclose in the form of the PSLRA's safe harbor. Given that pre-existing incentive, however, the mandate likely had a differential effect on firms depending on what disclosure, if any, they had already been providing. If our prior hypotheses are correct, firms with high litigation risk had an incentive to disclose meaningful risk factor information prior to the mandate. Therefore, in the voluntary disclosure regime, we expect firms at greater risk of litigation to disclose significantly more risk factor information that is less boilerplate and more readable. Because the SEC also wants companies to provide detailed risk factor information while avoiding boilerplate and complex language, as discussed above, we expect that the mandate will induce firms that previously had little incentive to disclose (i.e., firms with low litigation risk) to produce more meaningful risk factor disclosures. Thus, in the mandatory disclosure regime, we expect the difference in the risk factor disclosures of high and low litigation risk firms to narrow or disappear. ${ }^{9}$ We summarize these predictions in our third hypothesis:

\footnotetext{
${ }^{9}$ This is not to suggest that the mandate would have no effect on high litigation risk firms that were previously disclosing risk factors. The SEC's adoption of a mandate implied that they would now be policing such disclosures through the review and comment process. Thus, the disclosure mandate could induce even previously-disclosing firms to be more diligent. Nevertheless, we expect any such changes to be small at the margin relative to the
} 
H3a: In the voluntary disclosure regime, firms at greater risk of litigation provide more risk factor disclosure that is less boilerplate and more readable.

H3b: In the mandatory disclosure regime, there is little or no difference in the attributes of meaningful risk factor disclosure (amount, boilerplate, and readability) between firms with high and low litigation risk.

\subsection{Risk Factors and Investors' Risk Assessments}

Risk factor disclosures, if meaningful, should allow investors to make more precise estimates of the risks associated with firms' expected future cash flows. Thus, the attributes of meaningful risk factor disclosures discussed above should be positively associated with the market's assessment of firm risk (i.e., beta and stock return volatility). However, our prior hypotheses also suggest that meaningful risk factor disclosure varies systematically with firms' disclosure incentives and the disclosure regime. In particular, we posit that firms at greater risk of litigation provide more meaningful risk factor disclosures, particularly during the voluntary disclosure regime. Thus, our final hypothesis is as follows:

H4: The information content of risk factor disclosures is positively associated with the market's assessment of firm risk, particularly for firms at high risk of litigation in the voluntary disclosure regime.

\section{Research Design}

\subsection{Sample Selection}

During the voluntary disclosure period, 1996-2004, firms did not report risk factors in a specific section of the $10-\mathrm{K}$, and hence there are no common markers indicating the beginning or end of the risk factor discussion that can be used to reliably extract this text using computeraided search and retrieval. Because the risk factor text must be manually identified and collected, we select a sample of firms for testing. To do this, we estimate firm-specific ex-ante

changes necessitated by the mandate for firms with low litigation risk. 
litigation risk for each year in the voluntary disclosure period and then select two subsamples one with high litigation risk and the other with low litigation risk.

We discuss the litigation risk model in Appendix A. The evidence indicates that only those observations in the top decile of estimated litigation risk have any substantive risk of being sued. Therefore, for our High Risk sample, we randomly select 5\% of firms from those that rank in the top decile in at least one year of the voluntary disclosure period, for a sample of 181 firms. The Low Risk sample consists of firms that never rank above decile 6 in the voluntary disclosure period. We use this cutoff because the maximum estimated litigation risk for decile $6(0.015)$ is less than the minimum for decile 10 (0.022), ensuring that litigation risk in the Low Risk sample does not exceed that of the High Risk firms. We again randomly select 5\% of the firms in this group, resulting in 112 Low Risk firms. To examine the effects of the risk factor disclosure mandate, we follow the sample of High Risk and Low Risk firms through the mandatory disclosure period, 2005-2010, for which we again obtain firm-specific litigation risk estimates for each year using the model described in Appendix A.

Table 1 reports the distribution of sample observations by litigation risk decile. By construction in the voluntary disclosure period, observations in the Low Risk sample never rank above decile 6. Even so, two-thirds of the observations cluster in deciles 1-3. Conversely, observations in the High Risk sample are skewed toward the highest risk deciles, with decile 10 containing one-quarter of the observations, and deciles 8-10 more than half the sample. Because we include all firm-years in our analysis, however, some observations fall into the lower deciles. The sample profile is similar in the mandatory disclosure period, suggesting that litigation risk is 
relatively stable over time. Specifically, observations in the Low Risk (High Risk) sample cluster in the extreme low (high) litigation risk deciles. ${ }^{10}$

\subsection{Risk Factor Disclosure Measures}

For each firm-year in the sample, we obtain the annual filing from the SEC's online EDGAR system and extract the risk factor text. During the voluntary disclosure period, the location of the risk factors varies, but is typically found in either Item 7 (Management Discussion and Analysis) or Item 1 (Business). During the mandatory disclosure period, the risk factors are located in Item 1A (Risk Factors). We develop three proxies to measure the properties of firms' risk factor disclosures discussed above in Section II.

To assess the amount of risk factor disclosure, we use the word count of the risk factors disclosure. As shown in Figure 1, Panel A, disclosure by the High Risk sample increases steadily over the sample period, from a median of 265 words in 1996 to 6,602 words in 2010. In contrast, disclosure by the Low Risk sample is relatively flat throughout the voluntary disclosure period, never exceeding 600 words at the median. However, there is a sharp increase in the amount of disclosure beginning in 2005 with the risk factor disclosure mandate. Even during the mandatory disclosure period, however, disclosure by the Low Risk sample is still typically less than half the level of the High Risk sample.

It is possible that the increase in the amount of risk factor disclosure over time reflects a general trend towards longer corporate disclosures (e.g., Francis et al. 2002; Li 2008) rather than a specific trend related to risk factors. Similarly, the difference between the High Risk and Low Risk samples could be driven by differences in these firms' general disclosure tendencies rather

\footnotetext{
${ }^{10}$ There are 30 observations in the Low Risk group that are in deciles 7-10 during the mandatory disclosure period. Because our objective is to study how firms' disclosure policies evolve across regulatory regimes, we retain these observations in our primary tests. Untabulated supplemental analysis reveals, however, that their exclusion does not alter inferences.
} 
than by litigation risk. Thus, we also examine the word count of risk factors relative to that of MD\&A. ${ }^{11}$ For the High Risk sample, the results in Figure 1, Panel B reveal a rapid increase in the relative amount of risk factor disclosure until 2000, when it levels off at approximately 50 percent of MD\&A. For the Low Risk sample, risk factors are approximately 10 percent of MD\&A until 2005, but under the disclosure mandate quickly converge to the same relative level as the High Risk sample.

Our second measure assesses the extent to which risk factors merely repeat language from the prior year. Theoretical and empirical work in linguistics shows that the frequency distribution of words in human languages is highly skewed; a few words are used very often but most words are used rarely (Manning and Schütze 1999). This distinctive distribution is more pronounced for word bigrams (a sequence of two adjacent words) and even more so for word trigrams (a sequence of three adjacent words). ${ }^{12}$ If the probability of a word occurring is low, the probability of it occurring in conjunction with others is even lower. Independently written documents, even if they are on the same or similar subjects or are written by the same author at different points in time, typically have few matching trigrams. ${ }^{13}$

To measure the extent to which risk factor disclosures are cut and paste from the prior year, we first convert each disclosure into a set of trigrams. The set of trigrams in the reference document, denoted $\mathrm{S}(\mathrm{A})$, is then compared with that of the comparison document, denoted $\mathrm{S}(\mathrm{B})$, and the resemblance between the two documents is determined as follows:

\footnotetext{
${ }^{11}$ During the voluntary disclosure period, some firms disclose their risk factors in the MD\&A section. We exclude the risk factor language from the MD\&A text in our analysis.

${ }^{12}$ For example, the sentence "A storm is forecast for today" has four overlapping trigrams: (a storm is), (storm is forecast), (is forecast for), (forecast for today).

${ }^{13}$ For example, Gibbon et al. (1997) reports that even in a sample of Wall Street Journal articles comprising over 38 million words, $77 \%$ of trigrams occurred only once. Lyon et al. (2001) investigates the use of $n$-grams as lexical features and finds that single words and bigrams have low power to identify similar text relative to trigrams. The ability to detect similar text is reduced for $n>3$.
} 


$$
\text { Resemblance }=\frac{|\mathrm{S}(\mathrm{A}) \cap \mathrm{S}(\mathrm{B})|}{|\mathrm{S}(\mathrm{A}) \cup \mathrm{S}(\mathrm{B})|},
$$

where $0 \leq$ Resemblance $\leq 1$. Two identical documents have a Resemblance score of 1 . We focus our analysis on one-year Resemblance scores, i.e., a comparison of risk factor disclosures for firm $i$ in year $t$ relative to year $t-1$. The Resemblance score thus provides a simple and intuitive measure of text similarity that is grounded in linguistics theory.

Figure 2, Panel A compares Resemblance scores for the High Risk and Low Risk samples. As expected, Resemblance is systematically lower for the High Risk sample, indicating that these firms annually revise risk factor disclosures to a greater extent than Low Risk firms. ${ }^{14}$ There is a sizeable drop in Resemblance, however, for the Low Risk sample in 2005, consistent with the dramatic increase in the amount of risk factor discussion by these firms to comply with the disclosure mandate shown in Figure 1. The decline was short-lived, however, as Resemblance for the Low Risk sample quickly rebounded to its pre-2005 level. There is also a smaller drop in Resemblance in 2005 for the High Risk sample, but the level is not outside of its historical range. Panel B compares the Resemblance of risk factors relative to that of MD\&A. The ratio is greater than one in all years for both the High Risk and Low Risk samples, indicating that risk factors are updated to a lesser extent than MD\&A. Nevertheless, there is relatively more boilerplate language in the risk factors of Low Risk firms throughout the voluntary disclosure period, only converging with the High Risk firms after the risk factor disclosure mandate.

\footnotetext{
${ }^{14}$ Nevertheless, the Resemblance scores in Figure 2 are quite high by usual standards; median Resemblance in the High (Low) Risk sample is approximately 0.61 (0.77). To put these findings in context, we examine one-year Resemblance scores between firms, i.e., for firm $i$ in year $t$ relative to firm $j$ in year $t-1$. For all permutations of firm pairings, mean (median) Resemblance is $0.02(0.01)$; the $99^{\text {th }}$ percentile is 0.07 . We find similar results for Resemblance between firms in the same year, i.e., for firms $i$ and $j$ in year $t$. These results are comparable to findings in other settings (e.g., Lyon et al., 2001; Bao and Malcolm, 2006), where the average Resemblance score typically ranges between 0.01 and 0.03 . Thus, the results in Figure 2 indicate that the year-to-year Resemblance in firms' risk factors is quite high, consistent with the SEC's concerns about boilerplate disclosure.
} 
Our third measure assesses the readability of the risk factor disclosures. Following prior research (e.g., Li 2008), we use the Fog Index of text complexity which measures readability as a function of syllables per word and words per sentence:

$$
\text { Fog }=(\text { words per sentence }+ \text { percent of complex words }) \times 0.40 \text {, }
$$

where complex words are defined as words with three syllables or more. Fog indicates the number of years of formal education a person of average intelligence would need to understand the text after reading it once, and thus a higher Fog score indicates a less readable document.

Figure 3, Panel A shows that High Risk firms generally provide more readable risk factor disclosures than Low Risk firms during the voluntary disclosure period. Following the risk factor mandate, readability improves substantially for the Low Risk firms. Conversely, there is some evidence that readability deteriorated for High Risk firms, although the level remained within its historical range. Relative to MD\&A, Panel B shows that the readability of risk factors for High Risk and Low Risk firms converged during the mandatory disclosure period. In all years, however, risk factors are more difficult to read than MD\&A, as evidenced by a ratio greater than one, consistent with the SEC's concerns regarding the use of "legalese" in risk factors.

Overall, the graphical evidence supports our predictions regarding the incentives of High Risk firms to voluntarily provide meaningful risk factor disclosures under the PSLRA and the subsequent effects of the disclosure mandate on Low Risk firms. We next develop the empirical models we use to formally test our hypotheses.

\subsection{Empirical Models}

To examine the association between litigation risk and risk factor disclosures, we estimate the following regression model: 


$$
\begin{aligned}
\text { Disclosure } & =\beta_{1} \text { Risk }+\beta_{2} \text { Disclosure_MDA }+\beta_{3} \text { Forward_MDA } \\
& +\beta_{4} \text { ScaledDisclosure }+\beta_{5} \text { BigN }+\beta_{6} \text { LogMVE }+\beta_{7} \text { MTB } \\
& +\beta_{8} \text { Delaware }+\beta_{9} \text { Restructure }+\beta_{10} \text { Segments }+\varepsilon
\end{aligned}
$$

where Disclosure indicates one of the three risk factor disclosure metrics discussed above, (i) Count, the natural log of one plus the number of words in the risk factors discussion, (ii) Resemblance, or (iii) Fog. The main variable of interest is the litigation risk proxy, Risk, an indicator variable equal to one if the firm is in the High Risk sample, and zero otherwise. H1 predicts that Risk is positively (negatively) associated with Count (Resemblance and Fog).

We report results for two alternative specifications of equation (3). The first specification pools all observations to estimate the average association between litigation risk and the three risk factor disclosure metrics across the sample period. The second specification allows the coefficient estimate on Risk to vary for the voluntary and mandatory disclosure regimes. To the extent that the disclosure mandate reduces or eliminates differences in firms' risk factor disclosures, $\mathrm{H} 3$ predicts that the coefficient estimate on Risk in the mandatory disclosure period will be insignificant and/or less than the coefficient estimate in the voluntary disclosure period.

To control for firms' general disclosure tendencies, we include Disclosure_MDA which indicates one of the three disclosure metrics calculated using the firm's MD\&A (exclusive of any risk factor disclosure). Specifically, Count_MDA is the natural log of the number of words, Resemblance_MDA is the one-year resemblance score, and Fog_MDA is the Fog Index for MD\&A. Including the relevant MD\&A disclosure measure not only mitigates concerns regarding correlated omitted variables, but also allows us to differentiate the characteristics of risk factors relative to other disclosures in the 10-K.

Forward_MDA is the number of forward-looking words in the firm's MD\&A divided by the total number of words in the MD\&A. When invoking safe harbor protection, firms typically 
indicate keywords which identify forward-looking statements. ${ }^{15}$ We read a sample of these invoking statements to formulate the list of forward-looking words shown in Appendix B. Firms that provide relatively more forward-looking disclosure, as indicated by the use of these keywords, likely have greater incentives to provide meaningful risk factor disclosures. ScaledDisclosure is an indicator variable equal to one for firms eligible to adopt the reduced disclosure requirements under the Smaller Reporting Company rule or its predecessor, Regulation S-B. Because of scaled reporting for these firms, they may be less likely to provide meaningful risk factor disclosures.

$B i g N$ is an indicator variable equal to one for one of the top-tier external auditors. ${ }^{16}$ Firms that invest in a high quality auditor may be more likely to provide high quality disclosures. $\log M V E$ is the natural $\log$ of the market value of equity. Prior research shows that disclosure quality is positively related to firm size (e.g., Lang and Lundholm 1993). Following Li (2008), we control for business risk using growth, as measured by the market-to-book ratio $(M T B)$, and complexity of operations using the number of business segments (Segments). Delaware is an indicator variable equal to one for firms incorporated in Delaware. Firms with greater exposure to shareholder lawsuits may choose to incorporate in Delaware because it affords more certain liability protection for officers and directors (Jagannathan and Pritchard 2013). This cautious attitude may also cause managers of these firms to provide more meaningful risk factors. We include Restructure, an indicator variable equal to one if the firm engaged in restructuring

\footnotetext{
${ }^{15}$ For example, Parlex Corp.'s 2003 10-K invokes statutory safe harbor protection as follows: "This document includes and incorporates forward-looking statements that are subject to a number of risks and uncertainties. All statements, other than statements of historical facts included or incorporated in this document, regarding our strategy, future operations, financial position and estimated revenues, projected costs, prospects, plans and objectives of management are forward-looking statements. When used in this document, the words "will," "believe," "anticipate," "intend," "estimate," "expect," "project" and similar expressions are intended to identify forwardlooking statements, although not all forward-looking statements contain these identifying words."

${ }^{16}$ During our sample period, the top-tier auditors are Arthur Andersen, Deloitte \& Touche, Ernst \& Young, KPMG, and PricewaterhouseCoopers.
} 
activity, as a control for financing activities that could affect the quality of disclosure. Finally, we include year fixed effects.

To examine whether firms' risk factor disclosures are sensitive to changes in litigation risk, we estimate the following regression model:

$$
\begin{aligned}
\Delta \text { Disclosure } & =\beta_{1} \text { IncRisk }+\beta_{2} \text { DecRisk }+\beta_{3} \Delta \text { Disclosure_MDA }+\beta_{4} \Delta \text { Forward_MDA } \\
& +\beta_{5} \text { ScaledDisclosure }+\beta_{6} \text { BigN }+\beta_{7} \text { LogMVE }+\beta_{8} M T B \\
& +\beta_{9} \text { Delaware }+\beta_{10} \text { Restructure }+\beta_{11} \text { Segments }+\varepsilon
\end{aligned}
$$

where $\Delta$ Disclosure indicates the change in one of the three risk factor disclosure metrics and $\triangle D i s c l o s u r e \_M D A$ is the change in the respective disclosure metric calculated for the firm's MD\&A (exclusive of any risk factor disclosure). IncRisk (DecRisk) is the change in the estimated probability of litigation for positive (negative) changes. $\triangle F$ Frward_MDA is the change in the number of forward-looking words in the firm's MD\&A divided by the total number of words in MD\&A. All other variables are as defined above.

To avoid the confounding effects of changes in disclosure associated with the risk factor disclosure mandate, we estimate the model separately for the voluntary (1996-2004) and mandatory (2006-2010) disclosure periods, excluding the transition period from 2004-2006. In other words, holding the disclosure regime constant, we test whether firms adjust their risk factor disclosures in response to changes in litigation risk. $\mathrm{H} 2$ predicts that IncRisk is positively (negatively) associated with $\Delta$ Count (AResemblance and $\Delta F o g$ ), with High Risk firms more responsive to increases in litigation risk than Low Risk firms. However, we do not expect the opposite proposition to hold; firms are unlikely to change their risk factor disclosure as litigation risk decreases. Thus, we expect the coefficient estimate on DecRisk to be insignificant.

To examine whether risk factor disclosures are associated with the market's assessment of firm risk, we estimate the following regression model: 


$$
\begin{aligned}
\text { Market Risk }_{\mathrm{t}+1} & =\beta_{1} \text { Disclosure }_{\mathrm{t}}+\beta_{2} \text { Disclosure_MDA }_{\mathrm{t}}+\beta_{3} \text { Forward_MDA }_{\mathrm{t}} \\
& +\beta_{4} \text { ScaledDisclosure }_{\mathrm{t}}+\beta_{5} \text { BigN }_{\mathrm{t}}+\beta_{6} \text { LogMVE }_{\mathrm{t}}+\beta_{7} \text { MTB }_{\mathrm{t}} \\
& +\beta_{8} \text { Delaware }_{\mathrm{t}}+\beta_{9} \text { Restructure }_{\mathrm{t}}+\beta_{10} \text { Segments }_{\mathrm{t}}+\beta_{11} \text { MarketRisk }_{\mathrm{t}}+\varepsilon
\end{aligned}
$$

where Market Risk indicates either Beta, the slope coefficient from a regression of daily returns on the CRSP equal-weighted market index, or Std_AbRet, the standard deviation of daily abnormal stock returns, both measured over the 250 trading days beginning two days after the release of the $10-\mathrm{K}$ for year $t$. We include the determinants of risk factor disclosures from equation (3) to control for the expected level of disclosure. We also control for market risk, Beta or Std_AbRet, at time $t$.

We report results for two alternative specifications of equation (5). The first specification allows Disclosure to vary for High Risk and Low Risk firms to examine how disclosure incentives affect the informativeness of risk factor disclosures for future market-based measures of firm risk. The second specification allows the coefficient estimates on Disclosure to vary with both firms' disclosure incentives (High Risk or Low Risk) and across the disclosure regime (Voluntary or Mandatory). H4 predicts that for High Risk firms Market Risk $k_{t+1}$ is positively (negatively) associated with Count (Resemblance and Fog).

\section{Results}

\subsection{Descriptive Statistics}

Table 2 presents descriptive statistics for the regression variables. Panel A (Panel B) compares mean and median values across the High Risk and Low Risk samples for the voluntary (mandatory) disclosure period. In the voluntary disclosure period, Count is significantly higher in the High Risk sample and Resemblance and Fog are significantly lower, as predicted. ${ }^{17}$ In the

\footnotetext{
${ }^{17}$ Note that Fog is undefined for observations with zero word count and Resemblance is undefined for observations zero word count in either the current or prior year. Hence, the number of available observations for these two measures is less than the full sample size.
} 
mandatory disclosure period, the differences in Count and Resemblance between the High Risk and Low Risk samples narrow, with the difference for Resemblance insignificant at the mean. More striking, Fog is significantly higher in the High Risk sample.

In general, the disclosure patterns in MD\&A parallel those found in the risk factors; specifically, Count_MDA is higher and Resemblance_MDA is lower in the High Risk sample. It is interesting to note, however, that resemblance is uniformly lower for MD\&A relative to the risk factors, suggesting that firms tend to update MD\&A to a much greater extent. Fog_MDA is significantly higher for High Risk firms in both disclosure regimes, suggesting a general tendency for these firms to provide more complex disclosures.

High Risk firms use more forward-looking words in their MD\&A, although the difference is significant only in the voluntary disclosure period. In both periods, a significantly higher proportion of the Low Risk sample is eligible for scaled disclosure. Moreover, the proportion increases between the voluntary and mandatory disclosure periods in both the Low Risk and High Risk samples, consistent with SEC rules expanding the number of eligible smaller companies. Finally, High Risk firms are larger, have higher growth, are more likely to employ a top-tier auditor, incorporate in Delaware, and engage in restructuring activity.

Panel C of Table 2 presents a Pearson correlation matrix for the regression variables. As predicted, Risk is positively correlated with Count and negatively correlated with Resemblance and Fog, although the correlation with Fog is insignificant. Count is negatively correlated with both Resemblance and Fog, consistent with firms that provide more risk factor disclosure using less boilerplate and more readable language. Count, Resemblance, and Fog are all positively correlated with their corresponding MD\&A-based disclosure measure, demonstrating that firms adopt similar disclosure practices for both risk factors and MD\&A. Forward_MDA is positively 
correlated with Count but negatively correlated with Resemblance and Fog, suggesting that providing relatively more forward-looking information in the MD\&A is associated with longer risk factor sections that are updated to a greater extent and use more readable language. Finally, larger firms, as indicated by LogMVE and firms not eligible for ScaledDisclosure, and those using a top-tier auditor provide more discussion of risk factors and use less readable language.

\subsection{Regression Results}

Our first set of tests examines the association between litigation risk and the properties of risk factor disclosures in the voluntary and mandatory disclosure regimes. Table 3 presents results regarding the amount of risk factor disclosure. In the first specification reported in column (1), we find that the amount of risk factor disclosure is increasing in litigation risk, consistent with $\mathrm{H1a}$; on average, High Risk firms provide significantly more risk factor disclosure than Low Risk firms.

The results for the control variables indicate that firms providing more risk factor disclosure tend to be more verbose in general, as indicated by the positive and significant coefficient estimate on Count_MDA. Risk factors are also increasing with the amount of forward-looking disclosure (Forward_MDA), consistent with the incentives provided by the PSLRA's safe harbor. Finally, firms with a Big N auditor and firms incorporated in Delaware provide significantly more risk factor discussion, while large firms and firms with more business segments provide significantly less.

Findings for the second specification reported in column (2) of Table 3 show that High Risk firms disclose significantly more risk factor information in the voluntary disclosure regime, consistent with H3a. High Risk firms continue to be more forthcoming with risk factors in the mandatory regime, although the effect of litigation risk on disclosure is significantly reduced 
(i.e., the null hypothesis that the coefficient estimates on Risk are equal for the voluntary and mandatory disclosure periods is rejected at less than the 0.01 level). This finding supports $\mathrm{H} 3 \mathrm{~b}$.

Table 4 presents analogous results for boilerplate risk factor disclosure. Consistent with H1b, the negative and significant coefficient estimate on Risk in column (1) indicates that High Risk firms provide less boilerplate risk factor disclosure. In column (2), we find that this result holds in the voluntary disclosure regime, as predicted in H3a. However, the positive and significant coefficient estimate on Risk_Mandatory in column (2) suggests that High Risk firms use significantly more boilerplate language in the mandatory regime, counter to expectations. Recall from Figure 2 that Resemblance dropped precipitously for Low Risk firms in 2005 as these firms were forced to substantially update their risk factor disclosures to comply with the new mandate. Because Resemblance inherently captures differences in language across two years, including 2005 in the analysis could result in spurious inferences for the mandatory disclosure period. Consistent with this conjecture, untabulated robustness tests excluding 2005 observations reveal that the coefficient estimate on Risk_Mandatory is insignificant while that on Risk_Voluntary remains significantly negative. Thus, within the mandatory disclosure regime, this evidence supports the prediction in $\mathrm{H} 3 \mathrm{~b}$ that there is no statistical difference in boilerplate risk factor disclosure between firms with high and low litigation risk following the mandate.

Table 4 also shows that firms that tend to "cut and paste" risk factor disclosure follow the same practice with MD\&A, as evident from the positive and significant coefficient estimate on Resemblance_MDA. However, firms update their risk factors significantly more when they provide more forward-looking disclosure in their MD\&A. This finding suggests that firms are aware of the litigation risk posed by their forward-looking disclosures and take actions to avoid boilerplate warnings that are less likely to provide safe harbor protection. 
We examine the readability of risk factor disclosures in Table 5 . The results in column (1) indicate that High Risk firms use more readable language to describe their risk factors, consistent with H1c. This relation holds in both the voluntary and mandatory disclosure periods, as shown in column (2), although the results are statistically significant in the voluntary regime only. Taken together, these findings provide support for $\mathrm{H} 3 \mathrm{a}$ and $\mathrm{H} 3 \mathrm{~b}$. We also find that the readability of risk factor disclosures is positively associated with the readability of MD\&A, and that providing more forward-looking disclosure is associated with more readable risk factors.

Overall, the findings indicate that litigation risk provides a significant incentive for firms to disclose more meaningful risk factors (i.e., not only more disclosure but also disclosure that is less boilerplate and more readable). Firms that perceived little net benefit to disclosure (i.e., firms with low litigation risk) provided less meaningful disclosure on all three dimensions until disclosure was required by the SEC. Even then, firms at greater risk of litigation continue to provide significantly more risk factor disclosure, all else equal, suggesting that the mandate did not level disclosure practices completely. In other words, even in a mandatory disclosure regime, firm-specific incentives have an important influence on disclosure.

We examine whether firms change risk factor disclosures in response to changes in litigation risk in Table 6. Focusing first on changes in the amount of disclosure, we find that firms disclose significantly more risk factor information as litigation risk increases, as indicated by the positive and significant coefficient estimate on IncRisk in both the voluntary and mandatory disclosure periods. Untabulated findings reveal that this result is driven by the High Risk firms where the coefficient estimate on IncRisk is positive and significant at the $0.06(0.12)$ level in the voluntary (mandatory) disclosure period. In contrast, coefficient estimates for the Low Risk firms never approach significance at conventional levels. Thus, consistent with $\mathrm{H} 2$, we 
find that an increase in litigation risk, especially for firms already at a higher risk of being sued, is accompanied by an increase in risk factor discussion. Also consistent with expectations, Table 6 reveals insignificant results for DecRisk, suggesting that firms do not remove risk factor discussion when litigation risk falls. ${ }^{18}$ Regarding the control variables, the positive and significant coefficient estimate on $\triangle$ Count_MDA indicate that changes in MD\&A and risk factor disclosure tend to move in tandem. In addition, changes in forward-looking disclosure in the MD\&A (_Forward_MDA) are positively associated with changes in risk factor disclosure.

The results in the remaining columns of Table 6 provide no evidence that changes in litigation risk are associated with changes in the extent to which risk factor disclosures are boilerplate or readable. However, changes in boilerplate and readability are highly positively correlated with $\triangle$ Resemblance_MDA and $\triangle F o g_{-} M D A$, respectively, providing further evidence of correlated disclosure tendencies within firms' periodic filings.

Table 7 presents results for tests of the association between the amount of risk factor disclosure and the market's assessment of future firm risk. Pooling across disclosure regime, the findings reveal that Count is significantly positively associated with Beta $_{t+1}$ (column (1)) and Std_AbRet $t_{t+1}$ (column (3)) for High Risk firms only; there is no evidence of an association between risk factor disclosure and investors' risk assessments for firms with low litigation risk. ${ }^{19}$ These results are consistent with the evidence presented above showing that firms at greater risk of litigation provide more meaningful risk factor disclosures.

\footnotetext{
${ }^{18}$ We present results controlling for disclosure regime although we do not have any a priori reason to expect that the regime affects the sensitivity of risk factor disclosure to changes in litigation risk. Untabulated results reveal that the coefficient estimates on IncRisk and DecRisk are not significantly different between the voluntary and mandatory disclosure periods.

${ }^{19}$ Untabulated results indicate that the correlation is low between ex-ante litigation risk and either $\operatorname{Beta}_{t+1}(\rho=0.24)$ or $S t d \_A b \operatorname{Ret}_{t+1}(\rho=0.10)$. This can also be seen in our litigation risk model reported in Appendix A; these covariates are significantly associated with contemporaneous lawsuit filings in only two of the nine years in the voluntary disclosure period. Thus, there is no evidence of a mechanical association between litigation risk and either systematic or idiosyncratic firm risk.
} 
Columns (2) and (4) of Table 7 present results from a specification which allows the coefficient estimate on Count to vary for High Risk and Low Risk firms across the voluntary and mandatory disclosure regimes. In the voluntary disclosure regime, the findings indicate that the coefficient estimate on Count $_{\text {HighRisk }}$ is positive and significant for both market-based measures of future firm risk. In stark contrast, the coefficient estimate on Count $_{\text {LowRisk }}$ is negative, and significantly so with $S t d \_A b R e t_{t+1}$ as the dependent variable. Moreover, the null hypothesis that the coefficient estimates for the High Risk and Low Risk samples are equal is rejected at less than the 0.01 level. Thus, consistent with H4, High Risk firms provide significantly more informative risk factor disclosures in the voluntary disclosure regime.

In the mandatory disclosure regime, the coefficient estimates for High Risk and Low Risk firms are both significantly positive (insignificant) in the regression with $\operatorname{Std} \_\operatorname{AbRet}_{t+1}\left(\operatorname{Beta}_{t+1}\right)$ as the dependent variable. However, in both regressions, tests of coefficient differences are insignificant at conventional levels. Thus, consistent with the findings in our previous tests, the evidence is consistent with a convergence in the meaningfulness of risk factors after the disclosure mandate.

In additional untabulated analysis, we include Resemblance and Fog in the estimation of equation (5). Risk factor disclosures that are more boilerplate or less readable may be less informative to investors about future firm risk. We find, however, that the coefficients on these alternative risk factor disclosure metrics are insignificant. To further test the robustness of our results, we re-estimate the regressions in columns (2) and (4) of Table 7 substituting the change in the dependent variable for the level of the dependent variable with no change in inferences. We also implement a two-stage regression approach, where in the first stage we estimate the determinants model in equation (3) for Count (including the lagged value of Count as an 
additional explanatory variable). We then estimate a regression of $B_{e t a} t_{t+1}$ or $S t d \_A b R e t_{t+1}$ on this residual. Findings from both of these second stage estimations are consistent with our primary tests.

\section{Summary and Conclusion}

Risk factors disclosure has steadily increased, both in absolute terms and as a proportion of MD\&A, since Congress adopted the PSLRA in 1995, and continuing with the SEC's 2005 mandate. Risk factors now represent a substantial part of firms' annual securities filings. In this paper, we assess the effects of this shift from a voluntary incentive to a disclosure mandate.

Consistent with predictions, we find that prior to the SEC's 2005 mandate, firms with high securities litigation risk disclose more risk factors, revise their disclosure more from yearto-year, and use language that is easier to read. These findings are consistent with litigation risk providing an incentive for firms to voluntarily disclose risk factors that are more likely to be viewed as "meaningful" by the courts. With the advent of the SEC's mandate, these differences in disclosure largely disappear, although firms at higher risk of litigation continue to provide a greater amount of risk factor disclosure.

We also find that firms are sensitive to changes in litigation risk, but that this sensitivity is asymmetric. Firms experiencing an increase in litigation risk increase the amount of risk factor disclosure, but we do not find a corresponding decrease in disclosure when litigation risk declines. Moreover, this sensitivity is only displayed by high risk firms; we find no evidence that low risk firms are sensitive to changes in their litigation exposure.

Finally, we find that risk factor disclosures by firms at high risk of litigation are positively associated post-disclosure measures of firm risk, consistent with investors incorporating this information into their risk assessments. For low litigation risk firms, the 
association is insignificant, suggesting that disclosures by these firms convey little useful information. This difference is pronounced in the voluntary disclosure regime, but like our other results largely converges subsequent to the SEC's mandate.

Overall, we conclude from the evidence presented in this paper that firms with high litigation risk use risk factor disclosure in an effort to mitigate the expected costs of litigation. The SEC's introduction of a risk factor mandate induced substantial convergence in risk factor disclosure by firms at low risk of litigation. Nevertheless, the incentive to provide meaningful risk factor disclosure provided by the PSLRA may continue to affect disclosure decisions and the usefulness of risk factor disclosure for investors, at least for firms at high risk of securities fraud class actions. This paper contributes to our understanding of the roles of incentives and regulation in the evolution of narrative corporate disclosures, and its consequences for investors. The SEC's mandate in 2005 led to substantial convergence in risk factors disclosure, but scholars studying risk factor disclosure should be cognizant of the complementary role of legal incentives and regulatory mandates on disclosure decisions. 
Appendix A

Estimation of Firm-Specific Litigation Risk

We estimate the probability of litigation for each firm-year using the following model:

$$
\operatorname{Prob}(\text { Lawsuit }=1)=F\left(\begin{array}{l}
\alpha+\beta_{1} \text { Size }+\beta_{2} \text { Beta }+\beta_{3} \text { Cum } \_ \text {Ret }+\beta_{4} \text { Min_Ret }+\beta_{5} \text { Std_Ret } \\
+\beta_{6} \text { Skewness }+\beta_{7} \text { Turnover }+\beta_{8} \text { Biotech }+\beta_{9} \text { Hardware } \\
+\beta_{10} \text { Software }+\beta_{11} \text { Retail }+\beta_{12} \text { Electronic } s+\varepsilon
\end{array}\right)
$$

For notational convenience, we suppress year and firm subscripts.

Lawsuit is equal to one if the firm was a defendant in a class action securities lawsuit during the year, and zero otherwise. ${ }^{20}$ We use data from the Stanford Securities Class Action Clearinghouse to identify sued firms. Size is the natural log of the average of market value of common equity. Beta is the slope coefficient from a regression of daily returns on the CRSP equal-weighted market index. Cum_Ret is the cumulative daily return. Min_Ret is the minimum one day return. Std_Ret is the standard deviation of daily returns. Skewness is the skewness of the daily returns. Turnover is the proportion of shares traded, measured as $1-(1-\text { Turn })^{\mathrm{X}}$, where Turn is the average daily trading volume divided by the number of shares outstanding and $\mathrm{X}$ is the number of trading days. ${ }^{21}$ Prior research finds that Size, Beta, Std_Ret, and Turnover are positively associated with lawsuit filings, while Cum_Ret, Min_Ret, and Skewness are negatively associated with lawsuit filings. Finally, the model includes indicator variables for firms in five industries generally believed to be at higher risk of litigation than other industries, specifically Biotech (SIC codes 2833-2836), computer Hardware (SIC codes 3570-3577), computer Software (SIC codes 7371-7379), Retail (SIC codes 5200-5961), and Electronics (SIC codes 3600-3674). To the extent the firm-specific variables in the model do not capture cross-

\footnotetext{
${ }^{20} \mathrm{We}$ exclude lawsuits arising out of public offerings as the legal standards applicable to such lawsuits are substantially different and the PSLRA safe harbor does not apply to statements made in connection with initial public offerings.

${ }^{21}$ We divide daily trading volume for NASDAQ stocks by two to take into account differences in the way trading volume is reported on NASDAQ as opposed to NYSE and AMEX.
} 
sectional variation in litigation risk for firms in these industries, we expect the coefficient estimates on the industry indicator variables to be positive.

Table A1, Panel A reports summary statistics from the annual regressions of the litigation risk model for the voluntary disclosure period, 1996-2004. Coefficient estimates on four of the variables - Size, Cum_Ret,Min_Ret, and Turnover - are significant in the predicted direction in all nine annual estimations. The remaining firm-specific risk variables - Beta, Std_Ret, and Skewness - have coefficient estimates that are consistent with predictions in most of the annual estimations, but are generally not significant at the 0.05 level. The results for the industry indicator variables indicate that industry membership is not a significant determinant of litigation risk incremental to firm-specific factors.

Table A1, Panel B reports descriptive statistics for the estimated probability of litigation, ranked in deciles by year and pooled across years. Overall, the probability of litigation ranges from 0.000 to 0.992 , with a mean (median) of $0.023(0.007)$. The results reveal, however, that litigation risk is concentrated in the highest decile of firms. ${ }^{22}$ The mean (median) estimated litigation risk in decile 10 is $0.131(0.096)$, approximately three times higher than the mean (median) for decile 9. This evidence illustrates the highly skewed nature of the distribution of firms' litigation risk. In any given year, most firms face little or no risk of a securities fraud class action. Untabulated results for the estimation of the litigation risk model for the mandatory disclosure period, 2005-2010, yield similar inferences to those reported in Table A1.

\footnotetext{
${ }^{22}$ Because deciles are formed for each year, the maximum estimated litigation risk in a decile can exceed the minimum in higher deciles.
} 
Table A1

Estimation of Litigation Risk for the Voluntary Disclosure Period, 1996-2004

Panel A: Summary Statistics from Annual Logistic Estimations of Litigation Risk Model

\begin{tabular}{|c|c|c|c|c|}
\hline Variable & Prediction & $\begin{array}{l}\text { Mean Coefficient } \\
\text { Estimate }\end{array}$ & $\begin{array}{l}\text { \# positive / } \\
\text { \# negative }\end{array}$ & $\#$ significant ${ }^{\mathrm{a}}$ \\
\hline Intercept & $?$ & -5.10 & $0 / 9$ & 9 \\
\hline Size & + & 0.14 & $9 / 0$ & 9 \\
\hline Beta & + & 0.01 & $6 / 3$ & 2 \\
\hline Cum_Ret & - & -0.40 & $0 / 9$ & 9 \\
\hline Min_Ret & - & -3.08 & $0 / 9$ & 9 \\
\hline Std_Ret & + & -0.34 & $6 / 3$ & 2 \\
\hline Skewness & - & -0.03 & $2 / 7$ & 2 \\
\hline Turnover & + & 1.05 & $9 / 0$ & 9 \\
\hline Biotechnology & + & -0.48 & $5 / 4$ & 0 \\
\hline Computer Hardware & + & 0.05 & $5 / 4$ & 1 \\
\hline Computer Software & + & 0.03 & $4 / 5$ & 1 \\
\hline Electronics & + & 0.02 & $4 / 5$ & 0 \\
\hline Retail & + & -0.09 & $2 / 7$ & 0 \\
\hline $\begin{array}{l}\text { Mean Pseudo } \mathrm{R}^{2} \\
\text { Mean } \mathrm{N}\end{array}$ & $\begin{array}{c}0.27 \\
6,471\end{array}$ & & & \\
\hline
\end{tabular}

Panel B: Litigation Risk, Ranked in Deciles by Year

\begin{tabular}{ccccccc} 
Decile & $\mathrm{N}$ & Mean & Median & Std. Dev. & Minimum & Maximum \\
\hline 1 & 5,819 & 0.000 & 0.000 & 0.000 & 0.000 & 0.001 \\
2 & 5,826 & 0.001 & 0.001 & 0.001 & 0.000 & 0.003 \\
3 & 5,825 & 0.002 & 0.002 & 0.001 & 0.000 & 0.004 \\
4 & 5,826 & 0.004 & 0.004 & 0.002 & 0.000 & 0.006 \\
5 & 5,820 & 0.006 & 0.006 & 0.002 & 0.001 & 0.010 \\
6 & 5,826 & 0.009 & 0.009 & 0.003 & 0.001 & 0.015 \\
7 & 5,826 & 0.014 & 0.015 & 0.005 & 0.002 & 0.024 \\
8 & 5,825 & 0.022 & 0.023 & 0.007 & 0.004 & 0.036 \\
9 & 5,826 & 0.038 & 0.038 & 0.013 & 0.008 & 0.076 \\
10 & 5,819 & 0.131 & 0.096 & 0.105 & 0.022 & 0.992 \\
Total & 58,238 & 0.023 & 0.007 & 0.051 & 0.000 & 0.992
\end{tabular}




\section{Table A1 (continued) \\ Estimation of Litigation Risk for the Voluntary Disclosure Period, 1996-2004}

The litigation risk model estimated in Panel $\mathrm{A}$ is as follows:

$$
\operatorname{Prob}(\text { Lawsuit }=1)=F\left(\begin{array}{l}
\alpha+\beta_{1} \text { Size }+\beta_{2} \text { Beta }+\beta_{3} \text { Cum_Ret }+\beta_{4} \text { Min_Ret }+\beta_{5} \text { Std_Ret } \\
+\beta_{6} \text { Skewness }+\beta_{7} \text { Turnover }+\beta_{8} \text { Biotech }+\beta_{9} \text { Hardware } \\
+\beta_{10} \text { Software }+\beta_{11} \text { Retail }+\beta_{12} \text { Electronics }+\varepsilon
\end{array}\right)
$$

where Lawsuit is equal to one if the firm was a defendant in a class action securities lawsuit during the year, and zero otherwise. Size is the natural log of the average of market value of common equity. Beta is the slope coefficient from a regression of daily returns on the CRSP equal-weighted market index. Cum_Ret is the cumulative daily return. Min_Ret is the minimum one day return. Std_Ret is standard deviation of daily returns. Skewness is the skewness of the daily returns. Turnover is the proportion of shares traded, measured as $1-(1-\text { Turn })^{\mathrm{X}}$, where Turn is the average daily trading volume divided by the number of shares outstanding and $\mathrm{X}$ is the number of trading days. The high risk industry indicator variables represent Biotech (SIC codes 2833-2836), computer Hardware (SIC codes 3570-3577), computer Software (SIC codes 7371-7379), Retail (SIC codes 5200-5961), and Electronics (SIC codes 3600-3674).

a Significant in the predicted direction at the 0.05 level or better. Tests for all explanatory variables are one-sided; tests for the intercept are two-sided. 
Appendix B

Forward-Looking Words

\begin{tabular}{lclc}
\hline \multicolumn{1}{c}{ Word } & Frequency & \multicolumn{1}{c}{ Word } & Frequency \\
\hline Aim/aims & $0.02 \%$ & Ongoing & $0.82 \%$ \\
Anticipate/anticipates & 1.23 & Optimism/optimistic & 0.03 \\
Believe/believes & 4.14 & Outlook & 0.35 \\
Can/could & 9.50 & Pessimistic & 0.01 \\
Continue & 3.36 & Plan/plans & 5.41 \\
Contraction & 0.03 & Possible/possibility & 0.74 \\
Decline & 2.28 & Potential & 1.85 \\
Estimate/estimates & 5.93 & Predict/predicts/prediction & 0.43 \\
Expand/expansion & 1.80 & Probable/probability & 0.71 \\
Expect/expects/expectation & 3.38 & Project/projects/projection & 2.92 \\
Forecast/forecasts & 0.50 & Prospect/prospects & 0.20 \\
Future & 9.52 & See/sees & 3.19 \\
Goal & 0.17 & Seek/seeks & 0.50 \\
Grow/growth & 4.37 & Should & 1.62 \\
Hope/hopeful & 0.03 & Shrink & 0.06 \\
Intend/intends/intention & 0.72 & Target/targets & 0.43 \\
Look/looking & 1.87 & Trend/trends & 1.12 \\
May/might & 12.54 & Upbeat & 0.01 \\
Next & 0.96 & View/views & 0.23 \\
Objective & 0.22 & Will/would & 16.80 \\
& & & \\
\hline
\end{tabular}

This table reports forward-looking words used to invoke safe harbor protection identified from a search of 10-K filings and the relative frequency (in percentage terms) of these words in the sample firms' MD\&A. 


\section{References}

Baginski, S. P., J. M. Hassell, and M. D. Kimbrough. 2002. The Effect of Legal Environment on Voluntary Disclosure: Evidence from Management Earnings Forecasts Issued in U.S. and Canadian Markets. The Accounting Review 77: 25-50.

Bao, J-H., and J. A. Malcolm. 2006. Text Similarity in Academic Conference Papers. Working paper, University of Hertfordshire.

Bushee, B., and C. Leuz. 2005. Economic Consequences of SEC Disclosure Regulation: Evidence from the OTC Bulletin Board. Journal of Accounting and Economics 39: 233264.

Campbell, J., H. Chen, D. Dhaliwal, H. Lu, and L. Steele. 2014. The Information Content of Mandatory Risk Factor Disclosures in Corporate Filings. Review of Accounting Studies 19: 396-455.

Cheng, L, S. Liao, and H. Zhang, 2013. The Commitment Effect versus Information Effect of Disclosure - Evidence from Smaller Reporting Companies. The Accounting Review 88: 1239-1263.

Conference Report. 1995. Private Securities Litigation Reform Act of 1995." House of Representatives, Report No. 369, $104^{\text {th }}$ Congress, $1^{\text {st }}$ Session, 141 Congress Record H13699.

Ferrell, A. 2007. Mandated Disclosure and Stock Returns: Evidence from the Over-the-Counter Market, Journal of Legal Studies 36: 213-251.

Field, L., M. Lowry, and S. Shu. 2005. Does Disclosure Deter or Trigger Litigation? Journal of Accounting and Economics 39: 487-507.

Francis, J., D. Philbrick, and K. Schipper. 1994. Shareholder Litigation and Corporate Disclosures. Journal of Accounting Research 32:137-164.

Francis, J., K. Schipper, and L. Vincent. 2002. Expanded Disclosures and the Increased Usefulness of Earnings Announcements. The Accounting Review 77: 515-546.

Gibbon, D., R. Moore, and R. Winski. 1997. Handbook of Standards and Resources for Spoken Language Systems. Berlin: Mouton de Gruyter.

Greenstone, M., P. Oyer, and A. Vissing-Jorgensen. 2006. Mandated Disclosure, Stock Returns, and the 1964 Securities Acts Amendments. Quarterly Journal of Economics 1221: 399460 .

Jagannathan, M., and A. Pritchard. 2013. Do Delaware CEOs Get Fired? Working Paper, University of Michigan. 
Jarrell, G., 1981. The Economic Effects of Federal Regulation of the Market for New Security Issues. Journal of Law and Economics 24: 613-675.

Johnson, S. 2010. SEC Pushes Companies for More Risk Info. CFO Magazine (September): 16.

Johnson, M. F., R. Kasznik, and K. K. Nelson. 2000. Shareholder Wealth Effects of the Private Securities Litigation Reform Act of 1995. Review of Accounting Studies 5: 217-233.

Johnson, M. F., R. Kasznik, and K. K. Nelson. 2001. The Impact of Securities Litigation Reform on the Disclosure of Forward-Looking Information by High Technology Firms. Journal of Accounting Research 39: 297-327.

Johnson, M. F., K. K. Nelson, and A. C. Pritchard. 2007. Do the Merits Matter More? The Impact of the Private Securities Litigation Reform Act. Journal of Law, Economics, \& Organization 23: 627-652.

Jorion, P. 2002. How Informative are Value-at-Risk Disclosures? The Accounting Review 77: 911-931.

Kasznik, R., and B. Lev. 1995. To Warn or Not to Warn: Management Disclosures in the Face of an Earnings Surprise. The Accounting Review 70: 113-134.

Kothari, S., S. Shu, and P. Wysocki. 2009. Do managers withhold bad news? Journal of Accounting Research 47: 241-276.

Kravet, T., and V. Muslu. 2013. Informativeness of Risk Disclosures in Corporate Annual Reports. Review of Accounting Studies 18: 1088-1122.

Lang, M., and R. Lundholm. 1993. Cross-sectional Determinants of Analyst Ratings of Corporate Disclosures. Journal of Accounting Research 31: 246-271.

Li, F. 2006. Do Stock Market Investors Understand the Risk Sentiment of Corporate Annual Reports? Working paper, University of Michigan.

Li, F. 2008. Annual Report Readability, Current Earnings, and Earnings Persistence. Journal of Accounting and Economics 45: 221-247.

Li, F. 2010. Textual Analysis of Corporate Disclosures: A Survey of the Literature. Journal of Accounting Literature 29: 143-165.

Li, H., M. Pincus, and S. Rego. 2008. Market Reaction to Events Surrounding the SarbanesOxley Act of 2002 and Earnings Management. Journal of Law \& Economics 51: 111134.

Linsmeier, T., D. Thornton, M. Venkatachalam, and M. Welker. 2002. The Effect of Mandated Market Risk Disclosures on Trading Volume Sensitivity to Interest Rate, Exchange Rate, and Commodity Price Movements. The Accounting Review 77: 343-377. 
Lyon, C., J. Malcolm, and B. Dickerson. 2001. Detecting Short Passages of Similar Text in Large Document Collections, in Proceedings of Conference on Empirical Methods in Natural Language Processing.

Manning, C. D., and H. Schütze. 1999. Foundations of Statistical Natural Language Processing. Cambridge: The MIT Press.

PricewaterhouseCoopers. 2000 Securities Litigation Study. Manuscript available at www.10b5.com.

Pritchard, A. C., and H. A. Sale. 2005. What Counts as Fraud? An Empirical Study of Motions to Dismiss under the Private Securities Litigation Reform Act. Journal of Empirical Legal Studies 2:125-149.

Rajgopal, S. 1999. Early Evidence on the Informativeness of the SEC's Market Risk Disclosures: The Case of Commodity Price Risk Exposure of Oil and Gas Producers. The Accounting Review 74: 251-280.

Rogers, J. L., and A. Van Buskirk. 2009. Shareholder Litigation and Changes in Disclosure Behavior. Journal of Accounting and Economics 47: 136-156.

Securities and Exchange Commission (SEC), 1999. Division of Corporate Finance: Updated Staff Legal Bulletin No. 7 "Plain English Disclosure" (June 7).

SEC, 2005. Securities Act Rel. No. 33-8591, Securities Offering Reform.

Simon, C., 1989. The Effect of the 1933 Securities Act on Investor Information and the Performance of New Issues. The American Economic Review 79: 295-318.

Skinner, D. 1994. Why Firms Voluntarily Disclose Bad News. Journal of Accounting Research 32: $38-60$.

Skinner, D. 1997. Earnings Disclosure and Stockholder Lawsuits. Journal of Accounting and Economics 23: 249-282.

Stigler, G., 1964. Public Regulation of the Securities Markets. The Journal of Business 37: 117142.

You, H., and X. Zhang. 2009. Financial Reporting Complexity and Investor Underreaction to 10K information. Review of Accounting Studies 14: 559-586. 


\section{Figure 1}

Word Count of Risk Factors by Year

Panel A: Word count

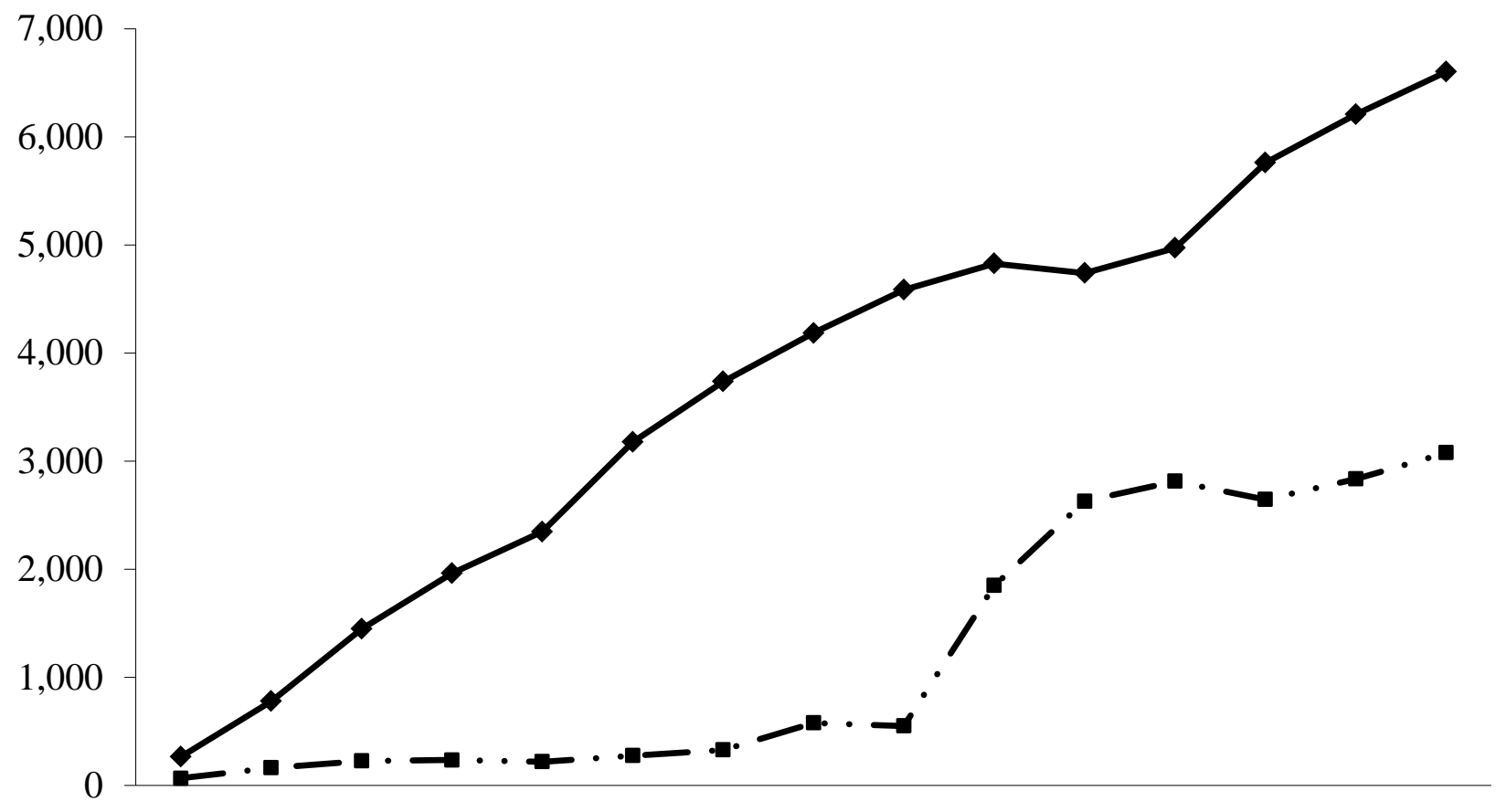

199619971998199920002001200220032004200520062007200820092010 $\rightarrow$-High Risk $\rightarrow$ Low Risk

Panel B: Relative to $M D \& A$

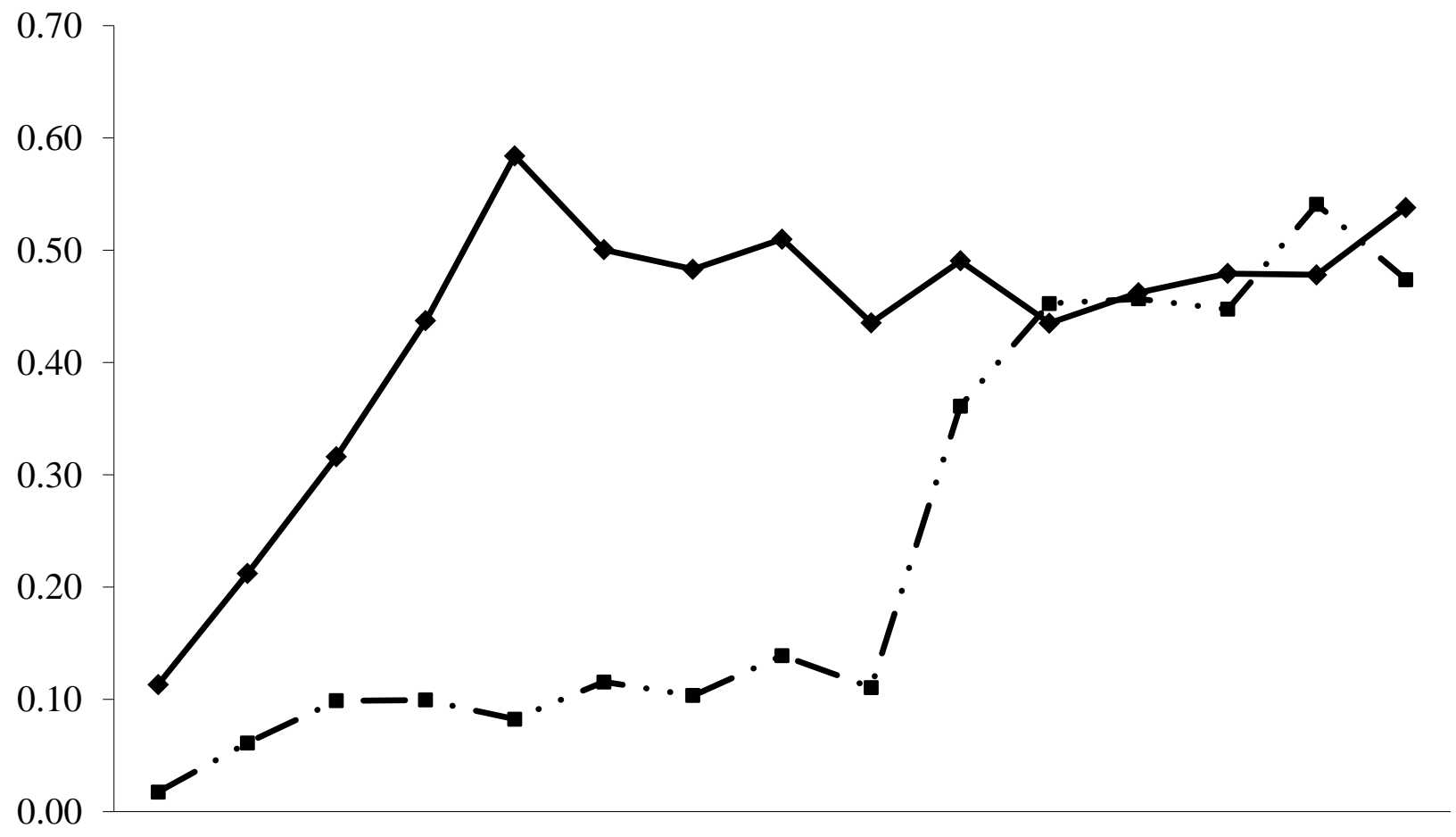

199619971998199920002001200220032004200520062007200820092010

$\rightarrow$ High Risk $\rightarrow$. Low Risk 
Figure 1 (continued)

Word Count of Risk Factors by Year

This figure presents the median word count of risk factors (Panel A) and the median ratio of the word count of risk factors divided by the word count of MD\&A (Panel B) for the High and Low Risk samples. 


\section{Figure 2}

Resemblance Score of Risk Factors by Year

Panel A: Resemblance score

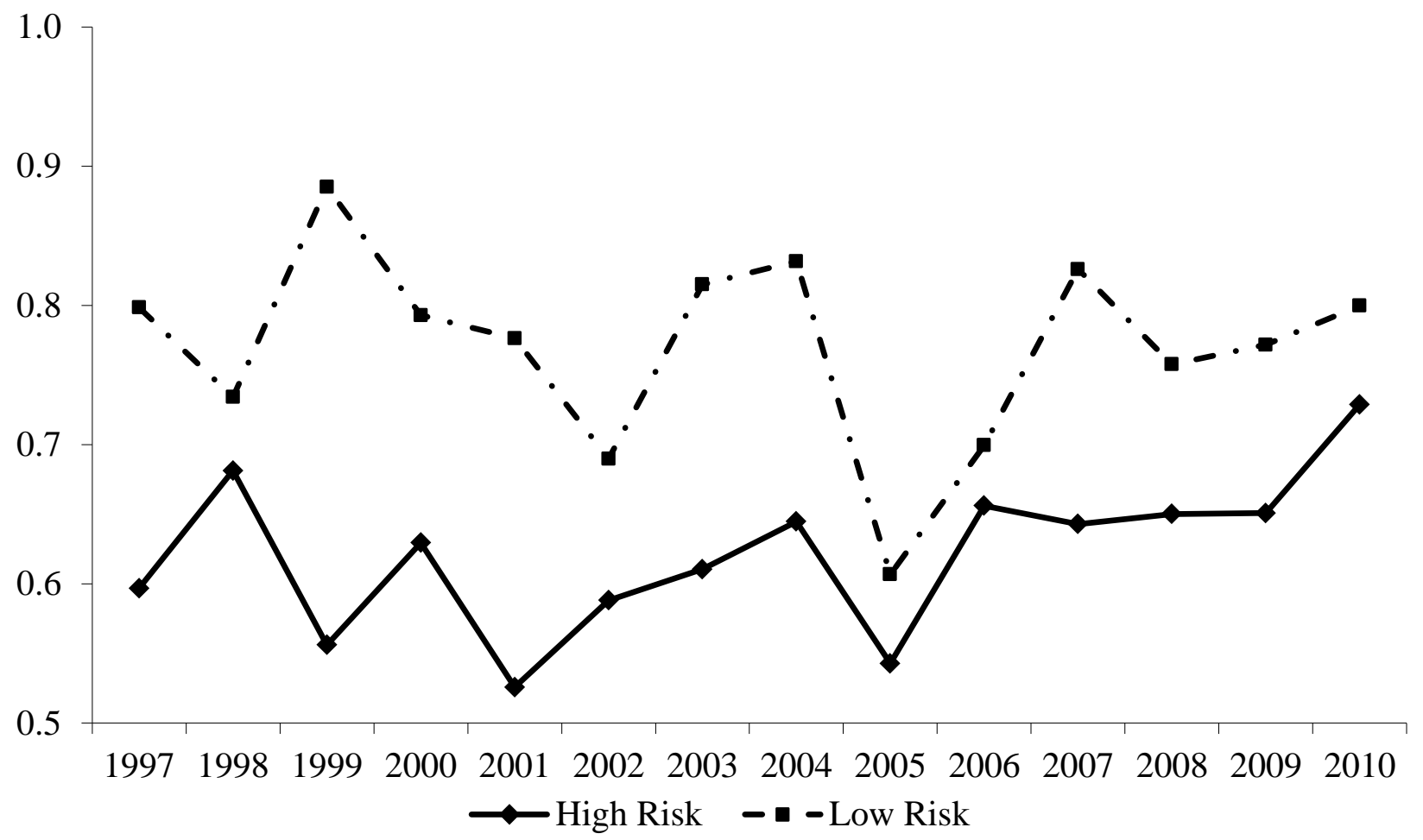

Panel B: Relative to $M D \& A$

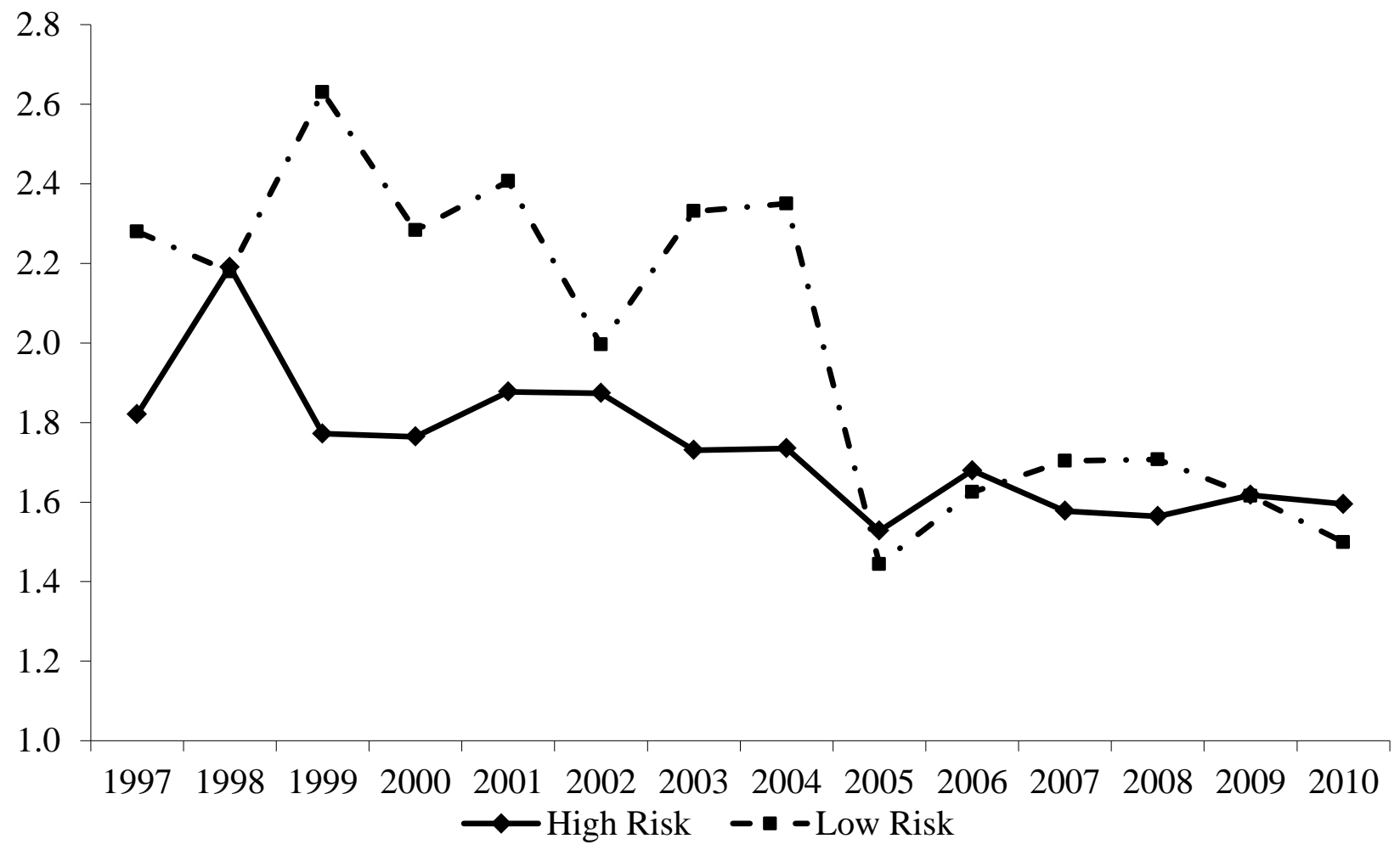




\section{FIGURE 2 (continued)}

\section{Resemblance Score of Risk Factors by Year}

This figure presents the median resemblance score of risk factors (Panel A) and the median ratio of the resemblance score of risk factors divided by the resemblance score of MD\&A exclusive of any risk factor language (Panel B) for the High and Low Risk samples. The resemblance score is calculated as $\frac{|\mathrm{S}(\mathrm{A}) \cap \mathrm{S}(\mathrm{B})|}{|\mathrm{S}(\mathrm{A}) \cup \mathrm{S}(\mathrm{B})|}$, where $\mathrm{S}(\mathrm{A})$ is the set of word trigrams (i.e., sequence of three adjacent words) in the reference document $A$ and $S(B)$ is the set of trigrams in the comparison document B. The figure shows one-year resemblance scores, i.e., a comparison of risk factor disclosures for firm $i$ in year $t$ relative to year $t-1$. 
Figure 3

Fog Index of Risk Factors by Year

Panel A: Fog index

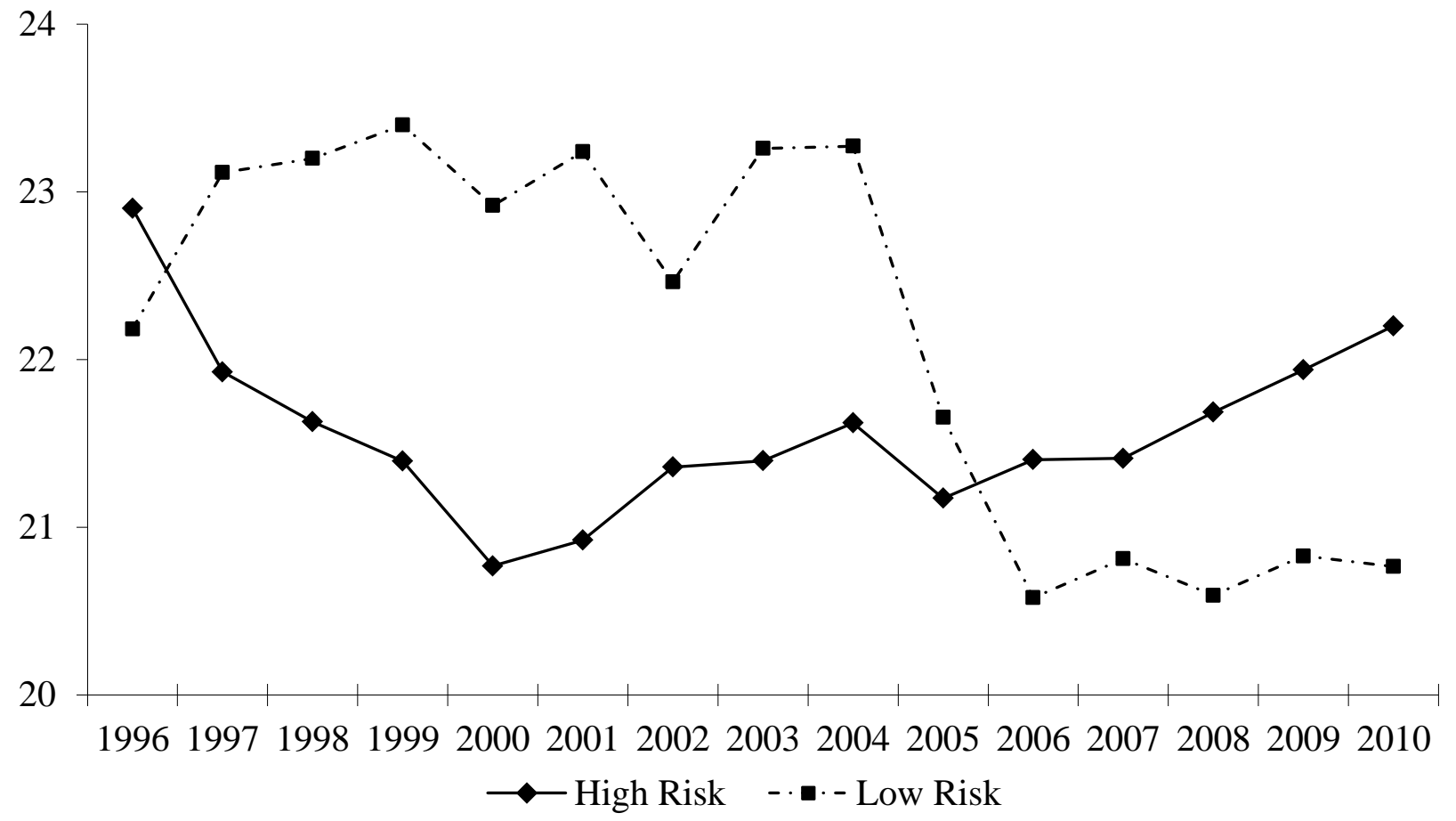

Panel B: Relative to $M D \& A$

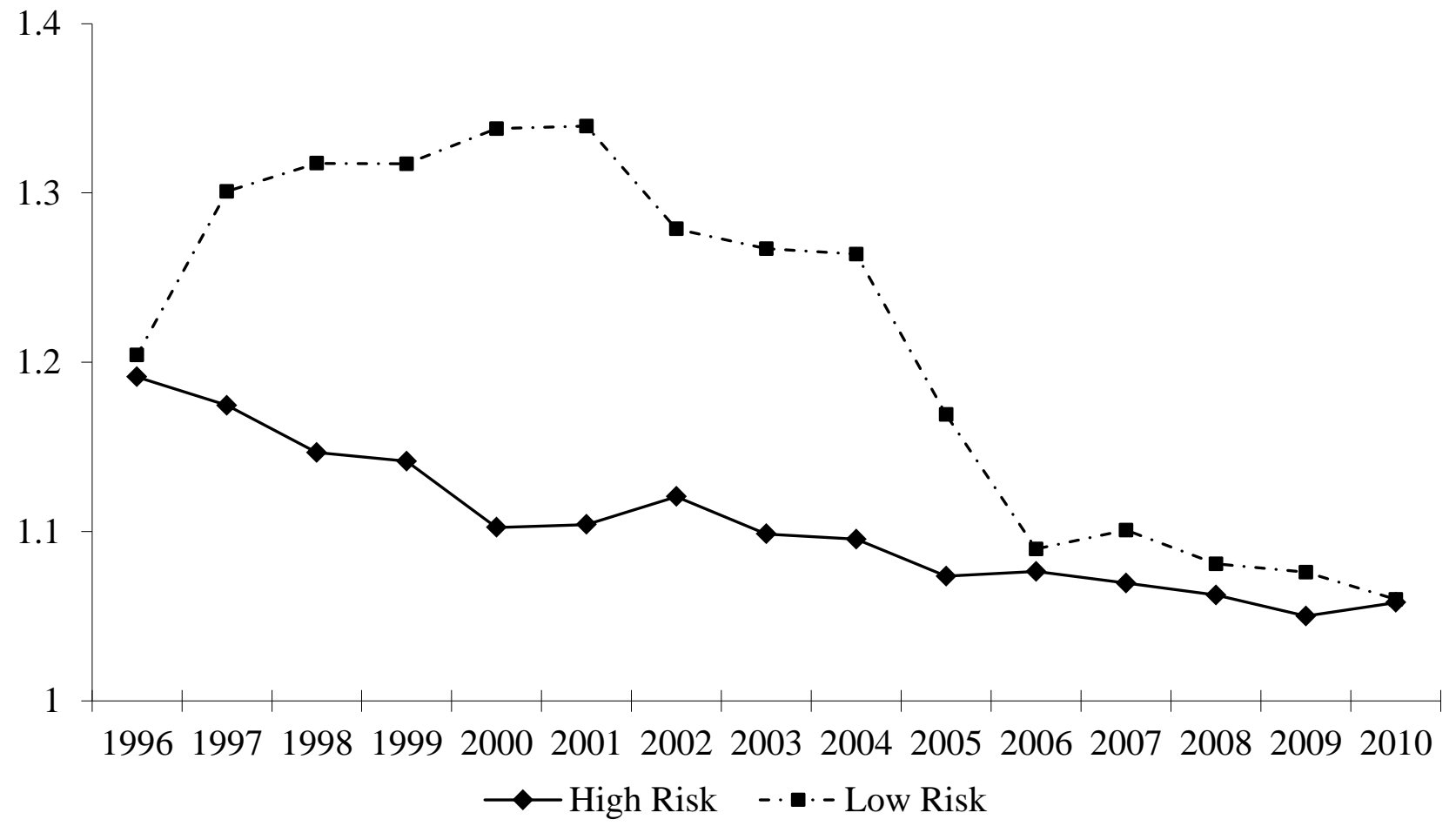




\section{FIGURE 3 (continued)}

\section{Fog Index of Risk Factors by Year}

This figure presents the median Fog Index of risk factors (Panel A) and the median ratio of the Fog Index for risk factors divided by the Fog Index for MD\&A exclusive of any risk factor language (Panel B) for the High and Low Risk samples. The Fog Index indicates the number of years of formal education a reader of average intelligence would need to understand the text after reading it once, and is calculated as (words per sentence + percentage of complex words $) \times 0.40$, where complex words are defined as words with three syllables or more. 
Table 1

Sample Observations by Litigation Risk Decile

\begin{tabular}{|c|c|c|c|c|}
\hline \multirow{2}{*}{$\begin{array}{l}\text { Litigation Risk } \\
\text { Decile }\end{array}$} & \multicolumn{2}{|c|}{$\begin{array}{c}\text { Voluntary Disclosure Period } \\
(1996-2004)\end{array}$} & \multicolumn{2}{|c|}{$\begin{array}{c}\text { Mandatory Disclosure Period } \\
(2005-2010)\end{array}$} \\
\hline & Low Risk & High Risk & Low Risk & High Risk \\
\hline 1 & 117 & 31 & 46 & 27 \\
\hline 2 & 137 & 44 & 47 & 24 \\
\hline 3 & 104 & 51 & 34 & 26 \\
\hline 4 & 85 & 69 & 28 & 23 \\
\hline 5 & 57 & 79 & 18 & 28 \\
\hline 6 & 37 & 95 & 18 & 39 \\
\hline 7 & & 120 & 9 & 37 \\
\hline 8 & & 132 & 11 & 60 \\
\hline 9 & & 189 & 6 & 57 \\
\hline 10 & & 267 & 4 & 77 \\
\hline Total & 537 & 1,077 & 221 & 398 \\
\hline
\end{tabular}

This table reports the number of observations in each litigation risk decile. The sample is constructed by first estimating firm-specific litigation risk annually for each year of the voluntary disclosure period (1996-2004) using the model specified in equation (A1) of the Appendix. High Risk firms are defined as those that rank in decile 10 in at least one year in the voluntary disclosure period. Low Risk firms are defined as those that never rank above decile 6 in any year in the voluntary disclosure period. A random sample of 181 (112) High Risk (Low Risk) firms is selected, representing approximately $5 \%$ of the firms in each risk group. The sample is then followed through the mandatory disclosure period (2005-2010). 
Table 2

Descriptive Statistics

Panel A: Distributional Statistics - Voluntary Disclosure Period

Test of Differences

Low Risk

High Risk $p$-value

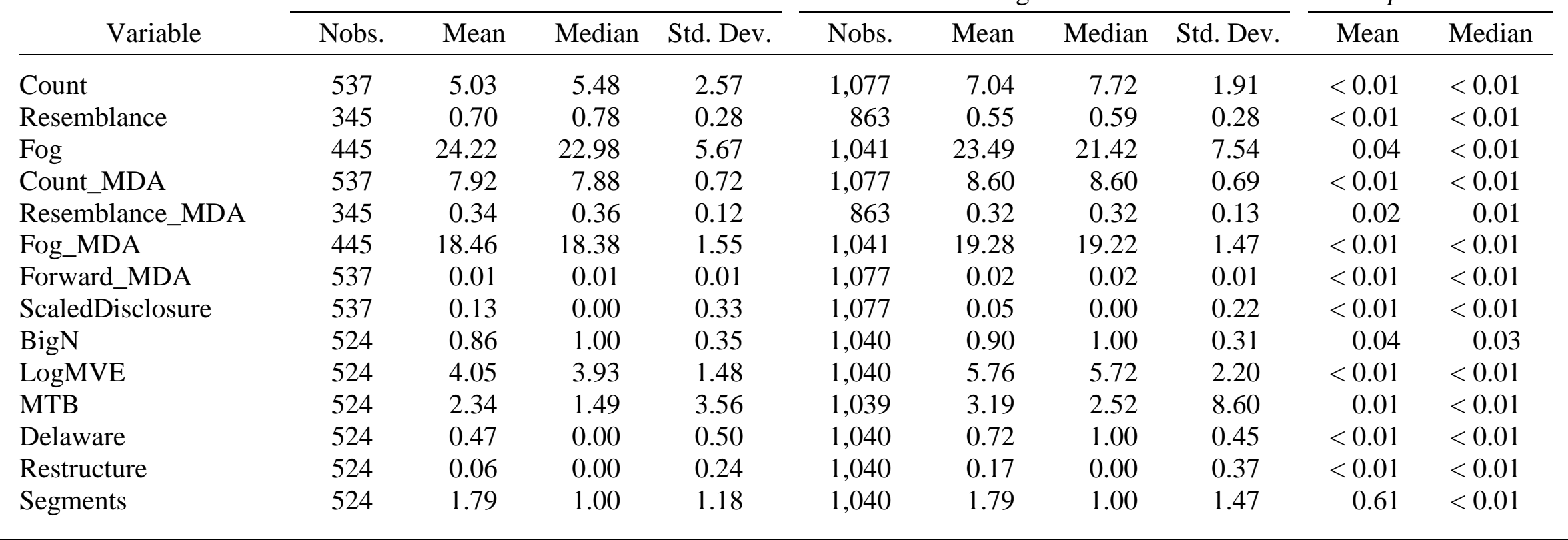


Table 2 (continued)

Descriptive Statistics

Panel B: Distributional Statistics - Mandatory Disclosure Period

Test of Differences

Low Risk

High Risk $p$-value

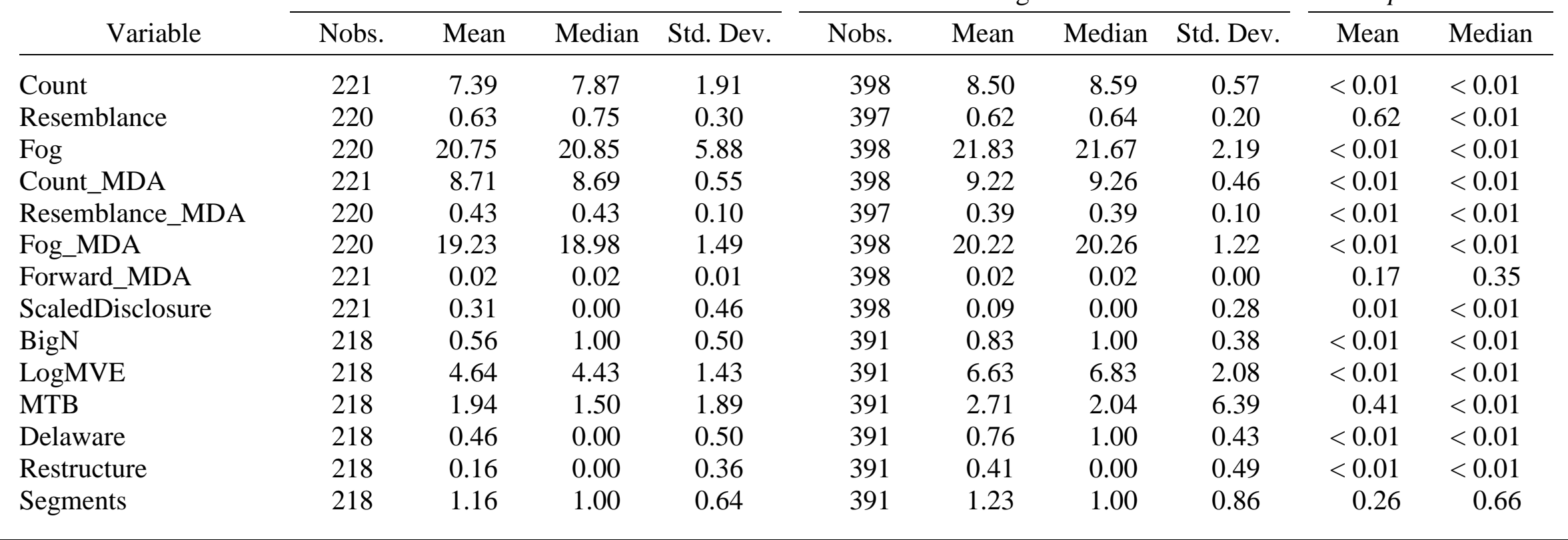


Table 2 (continued)

Descriptive Statistics

Panel C: Pearson Correlation Matrix

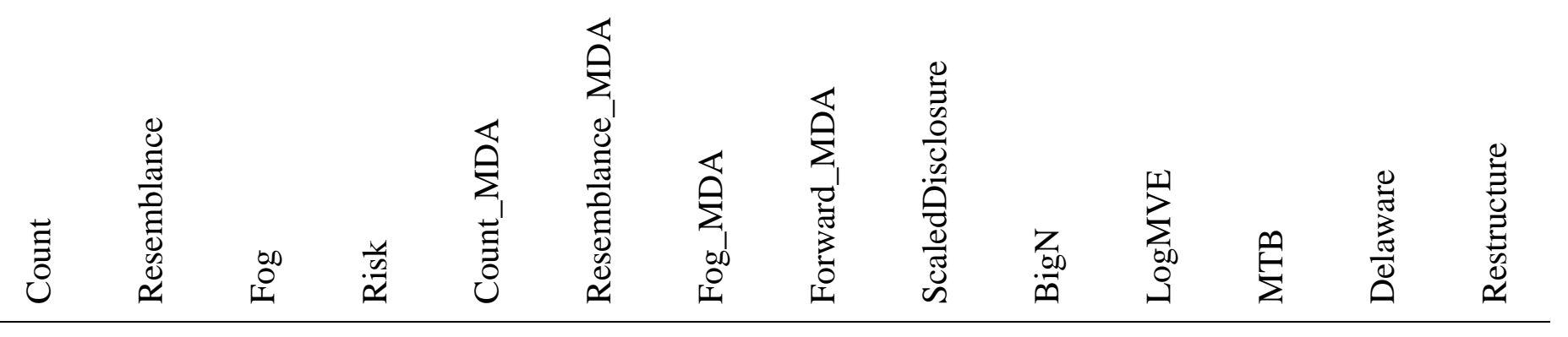

\begin{tabular}{|c|c|c|c|c|c|c|c|c|c|c|c|c|c|}
\hline Resemblance & -0.13 & & & & & & & & & & & & \\
\hline Fog & -0.24 & 0.09 & & & & & & & & & & & \\
\hline Risk & 0.36 & $-\mathbf{0 . 1 7}$ & -0.01 & & & & & & & & & & \\
\hline Count_MDA & 0.60 & -0.19 & -0.03 & 0.38 & & & & & & & & & \\
\hline Resemblance_MDA & 0.15 & 0.42 & -0.12 & -0.12 & 0.06 & & & & & & & & \\
\hline Fog_MDA & 0.40 & -0.11 & 0.06 & 0.24 & 0.50 & 0.10 & & & & & & & \\
\hline Forward_MDA & 0.31 & -0.09 & -0.12 & 0.09 & 0.21 & 0.10 & 0.18 & & & & & & \\
\hline ScaledDisclosure & -0.08 & 0.05 & -0.16 & -0.19 & -0.19 & 0.06 & $-\mathbf{0 . 0 7}$ & -0.04 & & & & & \\
\hline $\mathrm{BigN}$ & 0.10 & -0.04 & 0.10 & 0.14 & 0.12 & -0.07 & 0.06 & 0.09 & $-\mathbf{0 . 3 9}$ & & & & \\
\hline LogMVE & 0.27 & $-\mathbf{0 . 1 0}$ & 0.09 & 0.39 & 0.48 & -0.07 & 0.29 & 0.07 & -0.35 & 0.34 & & & \\
\hline MTB & 0.02 & 0.02 & -0.01 & 0.11 & -0.01 & 0.01 & 0.03 & 0.10 & 0.01 & -0.00 & 0.19 & & \\
\hline Delaware & 0.18 & -0.06 & 0.02 & 0.26 & 0.22 & -0.03 & 0.12 & 0.03 & -0.09 & 0.09 & 0.18 & 0.04 & \\
\hline Restructure & 0.24 & -0.06 & -0.06 & 0.18 & 0.39 & -0.03 & 0.20 & 0.02 & -0.07 & 0.07 & 0.21 & -0.03 & 0.12 \\
\hline Segments & -0.08 & -0.08 & 0.11 & 0.00 & 0.14 & -0.19 & 0.01 & -0.09 & $-\mathbf{0 . 1 0}$ & 0.04 & 0.10 & -0.08 & 0.03 \\
\hline
\end{tabular}

0.09 
Table 2 (continued)

Descriptive Statistics

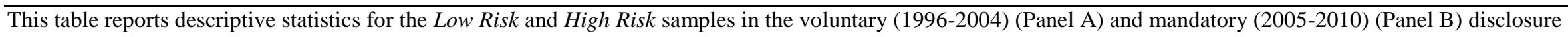
periods. Risk is and indicator variable equal to one (zero) for High (Low) Risk firms; Count is the natural log of the number of words in the risk factor disclosure;

Resemblance is calculated as $\frac{|\mathrm{S}(\mathrm{A}) \cap \mathrm{S}(\mathrm{B})|}{|\mathrm{S}(\mathrm{A}) \cup \mathrm{S}(\mathrm{B})|}$, where $\mathrm{S}(\mathrm{A})$ and $\mathrm{S}(\mathrm{B})$ are the set of trigrams (a sequence of three adjacent words in a sentence) in texts $\mathrm{A}$ and $\mathrm{B}$; Fog is the

number of years of formal education a reader of average intelligence would need to understand the text after reading it once, and is calculated as (words per sentence + percentage of complex words) $\times 0.40$, where complex words are defined as words with three syllables or more; Count_MDA, Resemblance_MDA, and Fog_MDA are calculated in an analogous fashion using MD\&A, exclusive of any risk factor disclosure; Forward_MDA is the number of forward-looking words in the firm's MD\&A (identified in Appendix B), divided by the total number of words in MD\&A; ScaledDisclosure is an indicator variable equal to one for firms able to adopt the reduced disclosure requirements under the Smaller Reporting Company rule or its predecessor, Regulation S-B; BigN equals one if the firm is audited by a top-tier auditor, and zero otherwise; $\log M V E$ is the natural $\log$ of the market value of equity; MTB is the market value of the firm divided by the book value of common equity; Delaware equals one if the firm is incorporated in Delaware, and zero otherwise; Restructure equals one if the firm engaged in restructuring activity, and zero otherwise; and Segments is the number of reported business segments.

Pearson correlations in Panel C significant at or below the 0.01 level (two-tailed) in Panel C are highlighted in boldface font. All reported $p$-values are two-tailed. 
Table 3

Association between Amount of Risk Factor Disclosure and Litigation Risk

\begin{tabular}{|c|c|c|c|c|}
\hline \multirow[b]{3}{*}{ Variable } & \multicolumn{4}{|c|}{ Dependent Variable $=$ Count } \\
\hline & \multicolumn{2}{|c|}{$(1)$} & \multicolumn{2}{|c|}{$(2)$} \\
\hline & $\begin{array}{c}\text { Coeff. } \\
\text { Est. }\end{array}$ & $p$-value & $\begin{array}{c}\text { Coeff. } \\
\text { Est. }\end{array}$ & $p$-value \\
\hline Risk & 1.14 & $<0.01$ & & \\
\hline Risk_Voluntary & & & 1.31 & $<0.01$ \\
\hline Risk_Mandatory & & & 0.67 & $<0.01$ \\
\hline Count_MDA & 0.71 & $<0.01$ & 0.74 & $<0.01$ \\
\hline Forward_MDA & 62.82 & $<0.01$ & 61.22 & $<0.01$ \\
\hline ScaledDisclosure & 0.09 & 0.48 & 0.08 & 0.54 \\
\hline $\mathrm{BigN}$ & 0.57 & $<0.01$ & 0.62 & $<0.01$ \\
\hline LogMVE & -0.06 & $<0.01$ & -0.07 & $<0.01$ \\
\hline MTB & 0.01 & 0.09 & 0.00 & 0.08 \\
\hline Delaware & 0.17 & 0.03 & 0.17 & 0.02 \\
\hline Restructure & -0.12 & 0.23 & -0.09 & 0.37 \\
\hline Segments & -0.14 & $<0.01$ & -0.14 & $<0.01$ \\
\hline Year Fixed Effects & Yes & & Yes & \\
\hline Adj. $\mathrm{R}^{2}$ & 0.95 & & 0.95 & \\
\hline Nobs. & 2,174 & & 2,174 & \\
\hline \multicolumn{5}{|c|}{$p$-value for Voluntary = Mandatory: } \\
\hline
\end{tabular}

See Table 2 for variable definitions. The voluntary (mandatory) disclosure period is 1996-2004 (2005-2010). All reported $p$-values are two-tailed. 
Nelson and Pritchard:

Table 4

Association between Boilerplate Risk Factor Disclosure and Litigation Risk

\begin{tabular}{|c|c|c|c|c|}
\hline \multirow[b]{3}{*}{ Variable } & \multicolumn{4}{|c|}{ Dependent Variable $=$ Resemblance } \\
\hline & \multicolumn{2}{|c|}{ (1) } & \multicolumn{2}{|c|}{ (2) } \\
\hline & $\begin{array}{l}\text { Coeff. } \\
\text { Est. }\end{array}$ & $p$-value & $\begin{array}{l}\text { Coeff. } \\
\text { Est. }\end{array}$ & $p$-value \\
\hline Risk & -0.05 & $<0.01$ & & \\
\hline Risk_Voluntary & & & -0.13 & $<0.01$ \\
\hline Risk_Mandatory & & & 0.07 & $<0.01$ \\
\hline Resemblance_MDA & 1.23 & $<0.01$ & 1.19 & $<0.01$ \\
\hline Forward_MDA & -3.74 & $<0.01$ & -3.73 & $<0.01$ \\
\hline ScaledDisclosure & 0.07 & $<0.01$ & 0.06 & $<0.01$ \\
\hline BigN & 0.04 & 0.04 & 0.02 & 0.37 \\
\hline LogMVE & 0.01 & $<0.01$ & 0.01 & $<0.01$ \\
\hline MTB & -0.00 & 0.21 & -0.00 & 0.21 \\
\hline Delaware & -0.00 & 0.95 & -0.00 & 0.81 \\
\hline Restructure & 0.00 & 0.81 & -0.01 & 0.73 \\
\hline Segments & 0.00 & 0.56 & 0.00 & 0.86 \\
\hline Year Fixed Effects & Yes & & Yes & \\
\hline Adj. $R^{2}$ & 0.86 & & 0.86 & \\
\hline Nobs. & 1,780 & & 1,780 & \\
\hline \multicolumn{5}{|c|}{$p$-value for Voluntary = Mandatory: } \\
\hline
\end{tabular}

See Table 2 for variable definitions. The voluntary (mandatory) disclosure period is 1996-2004 (2005-2010). All reported $p$-values are two-tailed. 
Table 5

Association between Readability of Risk Factor Disclosure and Litigation Risk

\begin{tabular}{|c|c|c|c|c|}
\hline \multirow[b]{3}{*}{ Variable } & \multicolumn{4}{|c|}{ Dependent Variable $=$ Fog } \\
\hline & \multicolumn{2}{|c|}{$(1)$} & \multicolumn{2}{|c|}{$(2)$} \\
\hline & $\begin{array}{c}\text { Coeff. } \\
\text { Est. }\end{array}$ & $p$-value & $\begin{array}{c}\text { Coeff. } \\
\text { Est. }\end{array}$ & $p$-value \\
\hline Risk & -1.41 & $<0.01$ & & \\
\hline Risk_Voluntary & & & -1.84 & $<0.01$ \\
\hline Risk_Mandatory & & & -0.36 & 0.53 \\
\hline Fog_MDA & 1.10 & $<0.01$ & 1.07 & $<0.01$ \\
\hline Forward_MDA & -155.36 & $<0.01$ & -151.63 & $<0.01$ \\
\hline ScaledDisclosure & -1.66 & $<0.01$ & -1.62 & $<0.01$ \\
\hline BigN & 0.29 & 0.51 & 0.17 & 0.70 \\
\hline LogMVE & 0.28 & $<0.01$ & 0.29 & $<0.01$ \\
\hline MTB & -0.02 & 0.58 & -0.02 & 0.58 \\
\hline Delaware & 0.12 & 0.69 & 0.12 & 0.70 \\
\hline Restructure & -0.99 & 0.01 & -1.05 & $<0.01$ \\
\hline Segments & 0.23 & 0.05 & 0.23 & 0.05 \\
\hline Year Fixed Effects & Yes & & Yes & \\
\hline Adj. $\mathrm{R}^{2}$ & 0.93 & & 0.93 & \\
\hline Nobs. & 2,049 & & 2,049 & \\
\hline \multicolumn{5}{|c|}{$p$-value for Voluntary = Mandatory: } \\
\hline
\end{tabular}

See Table 2 for variable definitions. The voluntary (mandatory) disclosure period is 1996-2004 (2005-2010). All reported $p$-values are two-tailed. 
Table 6

Association between Changes in Risk Factor Disclosure and Changes in Litigation Risk

\begin{tabular}{|c|c|c|c|c|c|c|}
\hline \multirow[b]{3}{*}{ Variable } & \multicolumn{6}{|c|}{ Dependent Variable } \\
\hline & \multicolumn{2}{|c|}{$\Delta$ Count } & \multicolumn{2}{|c|}{$\Delta$ Resemblance } & \multicolumn{2}{|c|}{$\Delta$ Fog } \\
\hline & $\begin{array}{c}\text { Coeff. } \\
\text { Est. }\end{array}$ & $p$-value & $\begin{array}{c}\text { Coeff. } \\
\text { Est. }\end{array}$ & $p$-value & $\begin{array}{c}\text { Coeff. } \\
\text { Est. }\end{array}$ & $p$-value \\
\hline IncRisk_Voluntary & 1236.69 & 0.05 & 0.16 & 0.40 & 0.95 & 0.75 \\
\hline IncRisk_Mandatory & 6844.22 & 0.09 & -0.62 & 0.26 & -12.70 & 0.16 \\
\hline DecRisk_Voluntary & 397.11 & 0.63 & -0.18 & 0.46 & -3.63 & 0.35 \\
\hline DecRisk_Mandatory & 1694.59 & 0.70 & -0.50 & 0.11 & -2.64 & 0.60 \\
\hline$\Delta$ Count_MDA & 0.18 & $<0.01$ & & & & \\
\hline$\Delta$ Resemblance_MDA & & & 0.99 & $<0.01$ & & \\
\hline$\Delta$ Fog_MDA & & & & & 0.61 & $<0.01$ \\
\hline$\Delta$ Forward_MDA & 399.62 & $<0.01$ & -0.00 & $<0.01$ & -0.00 & 0.13 \\
\hline ScaledDisclosure & -58.36 & 0.55 & -0.01 & 0.75 & -0.40 & 0.39 \\
\hline BigN & 52.70 & 0.50 & 0.00 & 0.94 & -0.31 & 0.39 \\
\hline LogMVE & 16.50 & 0.23 & 0.00 & 0.92 & -0.03 & 0.57 \\
\hline МTB & 6.57 & 0.34 & -0.01 & 0.74 & -0.02 & 0.59 \\
\hline Delaware & 66.26 & 0.26 & -0.01 & 0.82 & 0.07 & 0.78 \\
\hline Restructure & -117.11 & 0.13 & 0.01 & 0.66 & -0.06 & 0.87 \\
\hline Segments & -34.62 & 0.12 & -0.01 & 0.06 & -0.01 & 0.92 \\
\hline Year Fixed Effects & Yes & & Yes & & Yes & \\
\hline Adj. $\mathrm{R}^{2}$ & 0.16 & & 0.15 & & 0.01 & \\
\hline Nobs. & 1,645 & & 1,520 & & 1,765 & \\
\hline
\end{tabular}

$\Delta$ Count is the change in the number of words in the risk factor disclosure; $\Delta$ Resemblance is the change in the Resemblance score; $\Delta F o g$ is the change in the fog score; number of words in the MD\&A; Count_MDA, Resemblance_MDA, and Fog_MDA are calculated in an analogous fashion using MD\&A, exclusive of any risk factor disclosure; IncRisk (DecRisk) is the change in the estimated probability of litigation for positive (negative) changes in litigation risk; $\triangle$ Forward_MDA is the change in the ratio of forward-looking words in the firm's MD\&A to the total number of words in MD\&A. All other variables are defined in Table 2. To avoid the confounding effects of changes in disclosure associated with the risk factor disclosure mandate, we exclude the transition period from 2004-2006. Hence, the voluntary (mandatory) disclosure period is 1996-2004 (2006-2010). All reported $p$ values are two-tailed. 
Table 7

Risk Factor Disclosures and Future Market-Based Measures of Firm Risk

\begin{tabular}{|c|c|c|c|c|c|c|c|c|}
\hline \multirow[b]{3}{*}{ Variable } & \multicolumn{4}{|c|}{ Dependent Variable $=$ Beta $_{t+1}$} & \multicolumn{4}{|c|}{ Dependent Variable $=$ Std_AbRet $_{t+1}$} \\
\hline & \multicolumn{2}{|c|}{ (1) } & \multicolumn{2}{|c|}{ (2) } & \multicolumn{2}{|c|}{ (3) } & \multicolumn{2}{|c|}{ (4) } \\
\hline & Coeff. Est. & $p$-value & Coeff. Est. & $p$-value & Coeff. Est. & $p$-value & Coeff. Est. & $p$-value \\
\hline Count $_{\text {HighRisk }}$ & 0.0369 & 0.01 & & & 0.0008 & $<0.01$ & & \\
\hline Count $_{\text {LowRisk }}$ & 0.0120 & 0.21 & & & -0.0003 & 0.40 & & \\
\hline Count HighRisk_Voluntary $_{\text {_t }}$ & & & 0.0435 & $<0.01$ & & & 0.0006 & 0.05 \\
\hline Count HighRisk_Mandatory $_{\text {Hisk }}$ & & & 0.0142 & 0.48 & & & 0.0018 & $<0.01$ \\
\hline Count $_{\text {LowRisk_Voluntary }}$ & & & -0.0020 & 0.85 & & & -0.0010 & $<0.01$ \\
\hline Count $_{\text {LowRisk_Mandatory }}$ & & & 0.0162 & 0.45 & & & 0.0014 & 0.04 \\
\hline Count_MDA & 0.0275 & 0.01 & 0.0287 & 0.01 & 0.0044 & $<0.01$ & 0.0046 & $<0.01$ \\
\hline Forward_MDA & 0.0199 & 0.38 & 0.0164 & 0.47 & -0.0001 & 0.91 & 0.0001 & 0.98 \\
\hline ScaledDisclosure & 0.0103 & 0.85 & -0.0027 & 0.96 & 0.0079 & $<0.01$ & 0.0085 & $<0.01$ \\
\hline $\mathrm{BigN}$ & -0.0250 & 0.57 & 0.0024 & 0.70 & -0.0039 & $<0.01$ & -0.0036 & 0.01 \\
\hline LogMVE & 0.0293 & $<0.01$ & 0.0278 & $<0.01$ & -0.0035 & $<0.01$ & -0.0036 & $<0.01$ \\
\hline MTB & 0.0133 & $<0.01$ & 0.0137 & $<0.01$ & 0.0001 & 0.40 & 0.0001 & 0.40 \\
\hline Delaware & 0.0149 & 0.63 & 0.0154 & 0.61 & 0.0001 & 0.94 & 0.0001 & 0.96 \\
\hline Restructure & 0.0782 & 0.06 & 0.0958 & 0.02 & -0.0017 & 0.19 & -0.0014 & 0.30 \\
\hline Segments & -0.0114 & 0.36 & -0.0116 & 0.35 & -0.0006 & 0.13 & -0.0006 & 0.11 \\
\hline Beta $_{t}$ & 0.4934 & $<0.01$ & 0.4722 & $<0.01$ & & & & \\
\hline Std_AbRet $_{\mathrm{t}}$ & & & & & 0.6004 & $<0.01$ & 0.5922 & $<0.01$ \\
\hline Year Fixed Effects & Yes & & Yes & & Yes & & Yes & \\
\hline Adj. $R^{2}$ & 0.79 & & 0.79 & & 0.85 & & 0.85 & \\
\hline Nobs. & 2,015 & & 2,015 & & 1,949 & & 1,949 & \\
\hline \multicolumn{9}{|c|}{$p$-value for Count $_{\text {HighRisk }}=$ Count $_{\text {LowRisk: }}$ : } \\
\hline Pooled & & $<0.01$ & & & & $<0.01$ & & \\
\hline Voluntary & & & & $<0.01$ & & & & $<0.01$ \\
\hline Mandatory & & & & 0.79 & & & & 0.14 \\
\hline
\end{tabular}


Table 7 (continued)

Risk Factor Disclosures and Future Market-Based Measures of Firm Risk

\begin{abstract}
Beta $_{t+1}$ is the slope coefficient from a regression of daily returns on the CRSP equal-weighted market index and Std_AbRet $t_{t+1}$ is the standard deviation of daily abnormal stock returns, both measured over the 250 trading days beginning two days after the release of the $10-\mathrm{K}$. Count ${ }_{\mathrm{HighRisk}}\left(\mathrm{Count} \mathrm{LowRisk}_{\mathrm{B}}\right)$ is the natural log of the number of words in the risk factor disclosure for High Risk (Low Risk) firms. All other variables are defined in Table 2. The voluntary (mandatory) disclosure period is 1996-2004 (2005-2010). All reported $p$-values are two-tailed.
\end{abstract}

